\title{
Apparent source levels and active communication space of whistles of free-ranging Indo-Pacific humpback dolphins (Sousa chinensis) in the Pearl River Estuary and Beibu Gulf, China
}

Zhi-Tao Wang, Whitlow Au, Luke Rendell, Ke-Xiong Wang, Hai-Ping Wu, Yu-Ping Wu, Jian-Chang Liu, Guo-Qin Duan, Han-Jiang Cao, Ding Wang

Background. Knowledge of species-specific vocalization characteristics and their associated active communication space, the effective range over which a communication signal can be detected by a conspecific, is critical for understanding the impacts of underwater acoustic pollution, as well as other threats. Methods. We used a twodimensional cross-shaped hydrophone array system to record the whistles of free-ranging Indo-Pacific humpback dolphins (Sousa chinensis) in shallow-water environments of the Pearl River Estuary (PRE) and Beibu Gulf (BG), China. Using hyperbolic position fixing, which exploits time differences of arrival of a signal between pairs of hydrophone receivers, we obtained source location estimates for whistles with good signal-to-noise ratio $(S N R \geq 10 \mathrm{~dB})$ and not polluted by other sounds and back-calculated their apparent source levels. Combining with the masking levels (including simultaneous noise levels, masking tonal threshold, and the Sousa auditory threshold) and the custom made sitespecific sound propagation models, we further estimated their active communication space (ACS). Results. Humpback dolphins produced whistles with average root-meansquare apparent source levels (ASL) of $138.5 \pm 6.8$ (mean \pm standard deviation) and 137.2 $\pm 7.0 \mathrm{~dB}$ re $1 \mu \mathrm{Pa}$ in PRE $(\mathrm{N}=33)$ and $\mathrm{BG}(\mathrm{N}=209)$, respectively. We found statistically significant differences in ASLs among different whistle contour types. The mean and maximum ACS of whistles were estimated to be $14.7 \pm 2.6$ (median \pm quartiledeviation) and 17.1 $\pm 3.5 \mathrm{~m}$ in PRE, and $34.2 \pm 9.5$ and $43.5 \pm 12.2 \mathrm{~m}$ in BG. Using just the auditory threshold as the masking level produced the mean and maximum $\mathrm{ACS}_{\mathrm{at}}$ of $24.3 \pm 4.8$ and $35.7 \pm 4.6 \mathrm{~m}$ for PRE, and $60.7 \pm 18.1$ and $74.3 \pm 25.3 \mathrm{~m}$ for BG. The small ACSs were due to the high ambient noise level. Significant differences in ACSs were also observed among different whistle contour types. Discussion. Besides shedding some light for evaluating appropriate noise exposure levels and information for the regulation of underwater acoustic pollution, these baseline data can also be used for aiding the passive acoustic monitoring of dolphin populations, defining the boundaries of separate groups in a more 
biologically meaningful way during field surveys, and guiding the appropriate approach distance for local dolphin-watching boats and research boat during focal group following. 
1 Apparent source levels and active communication space of whistles of free-ranging Indo-

2 Pacific humpback dolphins (Sousa chinensis) in the Pearl River Estuary and Beibu Gulf,

3 China

4 Zhi-Tao Wang 1,2,3,*, Whitlow W. L. Au ${ }^{3}$, Luke Rendell ${ }^{4}$, Ke-Xiong Wang ${ }^{1}$, Hai-Ping Wu ${ }^{5}$, Yu-Ping Wu

$5 \quad{ }^{6}$, Jian-Chang Liu ${ }^{7}$, Guo-Qin Duan ${ }^{8}$, Han-Jiang Cao ${ }^{8}$, Ding Wang ${ }^{1}$

$6{ }^{1}$ The Key Laboratory of Aquatic Biodiversity and Conservation of the Chinese Academy of Sciences,

7 Institute of Hydrobiology, Chinese Academy of Sciences, Wuhan, P. R. China

$8 \quad{ }^{2}$ University of Chinese Academy of Sciences, Beijing, P. R. China

$9{ }^{3}$ Marine Mammal Research Program, Hawaii Institute of Marine Biology, University of Hawaii, Hawaii,

10 United States of America

$11{ }^{4}$ Sea Mammal Research Unit, School of Biology, University of St. Andrews, Fife, United Kingdom

$12{ }^{5}$ School of Marine Sciences, Qinzhou University, Guangxi, P. R. China

$13{ }^{6}$ School of Marine Sciences, Sun Yat-Sen University, Guangzhou, P. R. China

$14{ }^{7}$ Transport Planning and Research Institute, Ministry of Transport, Beijing, P. R. China

$15{ }^{8}$ Hongkong-Zhuhai-Macao Bridge Authority, Guangzhou, P. R. China

$16{ }^{*}$ Current address: Division of Marine Science and Conservation, Nicholas School of the Environment,

17 Duke University, Beaufort, NC, United States of America

18 Corresponding Authors:

19 Ke-Xiong Wang and Ding Wang 
20 7\# Donghu South Road, Wuhan, Hubei, 430074, China

21 Email address: wangk@ihb.ac.cn (KXW); wangd@ihb.ac.cn (DW) 


\section{Abstract:}

23 Background. Knowledge of species-specific vocalization characteristics and their associated active

24 communication space, the effective range over which a communication signal can be detected by a conspecific, is critical for understanding the impacts of underwater acoustic pollution, as well as other threats.

Methods. We used a two-dimensional cross-shaped hydrophone array system to record the whistles of free-ranging Indo-Pacific humpback dolphins (Sousa chinensis) in shallow-water environments of the Pearl River Estuary (PRE) and Beibu Gulf (BG), China. Using hyperbolic position fixing, which exploits time differences of arrival of a signal between pairs of hydrophone receivers, we obtained source location estimates for whistles with good signal-to-noise ratio $(\mathrm{SNR} \geq 10 \mathrm{~dB})$ and not polluted by other sounds and back-calculated their apparent source levels. Combining with the masking levels (including simultaneous noise levels, masking tonal threshold, and the Sousa auditory threshold) and the custom made sitespecific sound propagation models, we further estimated their active communication space (ACS).

Results. Humpback dolphins produced whistles with average root-mean-square apparent source levels (ASL) of $138.5 \pm 6.8$ (mean \pm standard deviation) and $137.2 \pm 7.0 \mathrm{~dB}$ re $1 \mu \mathrm{Pa}$ in PRE $(\mathrm{N}=33)$ and $\mathrm{BG}$ $(\mathrm{N}=209)$, respectively. We found statistically significant differences in ASLs among different whistle contour types. The mean and maximum ACS of whistles were estimated to be $14.7 \pm 2.6$ (median \pm quartile deviation) and 17.1 $\pm 3.5 \mathrm{~m}$ in PRE, and $34.2 \pm 9.5$ and $43.5 \pm 12.2 \mathrm{~m}$ in BG. Using just the

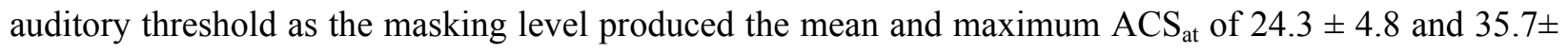
4.6 $\mathrm{m}$ for PRE, and $60.7 \pm 18.1$ and $74.3 \pm 25.3 \mathrm{~m}$ for BG. The small ACSs were due to the high ambient 
42 noise level. Significant differences in ACSs were also observed among different whistle contour types.

43 Discussion. Besides shedding some light for evaluating appropriate noise exposure levels and information

44 for the regulation of underwater acoustic pollution, these baseline data can also be used for aiding the

45 passive acoustic monitoring of dolphin populations, defining the boundaries of separate groups in a more

46 biologically meaningful way during field surveys, and guiding the appropriate approach distance for local

47 dolphin-watching boats and research boat during focal group following.

49 Keywords: Active communication space, Apparent source level, Beibu Gulf, Hydrophone arrays, Pearl

50 River Estuary, Indo-Pacific Humpback dolphins, Sousa chinensis, Sound propagation model, Whistles

51 Running title: Source level and communication range of Sousa whistle 


\section{Introduction}

54 Human activities have profoundly changed the world's aquatic environment. The International Union

55 for the Conservation of Nature (IUCN) suggests that nearly half of the extant marine mammal species are

56 threatened by two or more human impacts, and that a quarter of marine mammals have been classified as

57 threatened with extinction (Davidson et al. 2012). The Indo-Pacific humpback dolphins (Sousa chinensis,

58 locally called the Chinese white dolphin) is widely distributed throughout shallow, coastal waters from

59 eastern India in the west to the Southern China Sea in the east and throughout Southeast Asia (Jefferson

60 \& Rosenbaum 2014; Reeves et al. 2008). However, marine mammal species occurring in coastal areas are

61 most susceptible to risk, and the coastal distribution of the humpback dolphins make it highly vulnerable

62 to the impact of human activity (Davidson et al. 2012). Its conservation status was categorized as Near

63 Threatened by the IUCN Red List of Threatened Species (Reeves et al. 2008) and as a Grade One

64 National Key Protected Animal in China. Five resident populations of Indo-Pacific humpback dolphins

65 have been identified in Chinese coastal waters: the Pearl River Estuary (PRE) (Chen et al. 2010), Leizhou

66 Bay (Xu et al. 2015) of Guangdong, the Beibu Gulf (BG) of Guangxi (Chen et al. 2009; Pan et al. 2006),

67 Xiamen harbor of Fujian (Chen et al. 2009), and the West coast of Taiwan (Wang et al. 2012).

68 The PRE region (Fig. 1) is among the most economically developed regions in China (Yeung \& Shen

69 2008) and also home the world's largest known population of humpback dolphins (Chen et al. 2010;

70 Preen 2004), with the population size estimated to be over 2500 (CVs: $19-89 \%$ ) (Chen et al. 2010). The

71 BG region (Fig. 1) is, in comparison, relatively undeveloped, with a smaller human population, and the

72 humpback dolphin population there was estimated to be 251 (95\% CI of 136-794) (Chen et al. 2009; Pan 
73 et al. 2006). The concern about the effects of anthropogenic noise on aquatic life is growing world widely

74 (Popper \& Hawkins 2012), and economic growth in China has been accelerating human damage to

75 coastal ecosystems (He et al. 2014). The recent construction of the Hongkong-Zhuhai-Macao bridge

76 (Wang et al. 2014b), the Zhuhai wind-farm project in Pearl River Estuary, and the flourishing year round

77 dolphin-watching industry in Beibu Gulf (Wang et al. 2013) all have potentially adverse effects on

78 aquatic life. Pile-driving is likely to cause acoustic disturbance (Wang et al. 2014b), and the intense

79 dolphin-watching industry make the dolphin susceptible to close approaches by high-speed dolphin-

80 watching vessels. High-speed vessels can seriously affect the dolphins' natural behavior ( $\mathrm{Ng} \&$ Leung

81 2003), introduce masking noise (Sims et al. 2012a), and cause injury or even death (Jefferson 2000) to

82 resident cetaceans. Hence, concerns regarding the conservation of these Chinese white dolphin

83 populations are increasing.

Marine mammals, especially cetaceans, have evolved sophisticated sound production and reception

mechanisms to aid in meeting their requirements for a series of vital processes, including communication,

navigation, and foraging (Au 1993; Au \& Hastings 2008; Surlykke et al. 2014). Dolphins use frequency

87 modulated narrowband sounds, also called whistles, for communication with conspecifics (Janik 2000b;

Janik \& Slater 1998). Both whistle source level (SL), defined as the amplitude at $1 \mathrm{~m}$ from the animal on the acoustic axis (Janik 2000a) and its associated active communication space, the effective range over which a communication signal can be detected by a conspecific (Marten \& Marler 1977; Tervo et al. 2012) are fundamental parameters in animal communication systems. The source level is important because it 
93

94

95

96

97

98

99

100

101

102

103

104

105

106

107

exposed (Janik 2000a), which can shed some light on evaluating the appropriate exposure level of dolphins to anthropogenic noise. Knowledge of the statistical distribution of whistle source levels can help in planning passive acoustic monitoring studies of habitat use, as well as abundance estimates (Frankel et al. 2014; Šrović et al. 2007). However, the distance commonly used to identify dolphins as members of a group was either the '10-m chain rule' (any individuals considered part of the same group were within $10 \mathrm{~m}$ of at least one other member of the group, regardless of behavior) (Acevedo-Gutiérrez 2002; Acevedo-Gutiérrez \& Stienessen 2004; Connor et al. 2006; Quick \& Janik 2008; Quick \& Janik 2012; Smolker et al. 1992) or a radius of $100 \mathrm{~m}$ (a collection of individuals within which no dolphins were separated by greater than $100 \mathrm{~m}$ ) (Barco et al. 1999; Lewis et al. 2011), which may not be biologically meaningful. In conjunction with passive acoustic localization, many recorded whistles from a dolphin focal group (defined by 10-m chain rule) were confirmed to be produced by non-focal groups nearby, rather than the defined focal group (Quick \& Janik 2008). As well, the estimated whistle active space in previous studies of odontocetes were mismatched with, and always greater than, the separation distances commonly used to define the boundary of separate groups (Janik 2000a; Miller 2006; QuintanaRizzo et al. 2006). Additionally, with the increasing threaten of the acoustic masking in marine ecosystems by anthropogenic noise(Clark et al. 2009), the active communication space can help to define the boundary of separate dolphin groups in a more biologically meaningful way.

Humpback dolphin can emit pulsed sound with a peak frequency of $114 \pm 12 \mathrm{kHz}$ and an apparent source level of $199 \pm 3 \mathrm{~dB}$ re $1 \mu \mathrm{Pa} @ 1 \mathrm{~m}$ (peak-to-peak)(Freitas et al. 2015). As well, they can produce whistles with fundamental frequencies averaged $6.4 \mathrm{kHz}$, and minimum and maximum fundamental 
113 frequencies averaged $5.1 \mathrm{kHz}$ and $7.7 \mathrm{kHz}$, respectively (Wang et al. 2013). Although S. chinensis is a

114 common species in many waters, information about its vocal behavior remains sparse (Hoffman et al.

115 2015; Kimura et al. 2014; Li et al. 2012; Wang et al. 2013; Wang et al. 2015). The regulation of

116 underwater acoustic pollution is currently constrained by sparse data, especially the scarcity of

117 quantitative data on animal vocalization characteristics and effects of anthropogenic noise on the

118 biological functions, such as acoustically mediated social interactions (NRC 2005). In order to avoid or to

119 mitigate the possible detrimental impact and to better protect these Sousa populations, basic acoustic

120 information is needed.

121 While, the apparent source level of whistles, defined as the back-calculated sound pressure level at $1 \mathrm{~m}$

122 distance from the sound source at an unknown angle from the acoustic axis (Jensen et al. 2009b), and its

123 active communication space were estimated in many cetaceans, such as in bottlenose dolphin (Tursiops

124 truncatus) (Jensen et al. 2012) and in white-beaked dolphins (Lagenorhynchus albirostris) (Rasmussen et

125 al. 2006), relevant information is barely known in humpback dolphin. In this study, by using passive

126 acoustic localization, the apparent source level of whistles produced by free-ranging S. chinensis in Pearl

127 River Estuary and Beibu Gulf were measured. The active communication space of whistles were further animal physiological hearing capabilities and critical ratios.

\section{Methods}


133

134

135

136

137

138

\section{Data collection}

Acoustic recordings were made during June-July, 2014, in PRE $\left(22^{\circ} 06^{\prime}-22^{\circ} 11^{\prime} \mathrm{S} ; 113^{\circ} 40^{\prime}-113^{\circ} 45^{\prime} \mathrm{E}\right)$

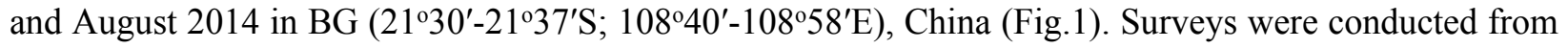
a $7.5 \mathrm{~m}$ recreational powerboat with a $140 \mathrm{hp}$ outboard engine in PRE or a $6.8 \mathrm{~m}$ dolphin-watching vessel powered by $40 \mathrm{hp}$ outboard engine in BG under Beaufort sea states $\leq 3$ (on a scale of 12) with a randomly selected route rather than structured transects.

When a group of dolphins was sighted and the majority of whose members were engaged in slow or moderate movements (resting, milling, socializing or feeding) (Hawkins \& Gartside 2009), the vessel moved position to the side of the dolphin group. Groups were defined by the ' $10 \mathrm{~m}$ chain rule' (Quick \& Janik 2012). If the dolphin group was traveling fast (Hawkins \& Gartside 2009), the boat would move swiftly ahead of their moving direction to await them passing by. During sound recording, the vessel's engine was turned off. For each animal group, the GPS time, location (latitude and longitude), dolphin species, and behavior (traveling, socializing, milling, resting, and feeding) (Hawkins \& Gartside 2009) were recorded. The water depth and water quality, including temperature, salinity, and $\mathrm{pH}$, were measured with a Horiba Multi-parameter Water Quality Monitoring System (model W-22XD; Horiba, Ltd., Kyoto, Japan) for sound propagation modeling. Recording was stopped when none of the dolphins of a group were within $50 \mathrm{~m}$ to the hydrophone arrays.

The two-dimensional cross-shaped array consisted of five Reson piezoelectric hydrophones, one in the middle and four on each end of the arms (model TC-4013, frequency range $1 \mathrm{~Hz}$ to $170 \mathrm{kHz}$, sensitivity: $211 \mathrm{~dB} \pm 3 \mathrm{~dB}$ re $1 \mathrm{~V} / \mu \mathrm{Pa}$; Reson Inc., Slangerup, Denmark) (Fig.2). Each hydrophone was equipped 
153

154

with a $1 \mathrm{MHz}$ bandwidth Reson EC6081 voltage pre-amplifier with a band-pass filter (model VP2000, pass-band 0.1 to either $100 \mathrm{kHz}$ or $250 \mathrm{kHz}$ depending on sampling rate). The EC6081 employ the first order filters (one pole), which was a filter slope of $6 \mathrm{~dB} /$ octave in frequency. The hydrophones were connected via a 16-channel synchronized analogue-to-digital (A/D) converter to a laptop computer running LabVIEW 2011 SP1 software (National Instruments (NI), Austin, TX, USA). The A/D converter consisted of four high-speed, 16 bit resolution, data acquisition (DAQ) modules (NI 9223), incorporated in a compact DAQ four-slot USB chassis (NI cDAQ-9174). Each NI 9223 was a four-channel simultaneous $\mathrm{A} / \mathrm{D}$ converter with a sample rate up to $1 \mathrm{MHz}$ for each channel. Both VP2000 amplifier and NI cDAQ-9174 were powered by external battery packs.

A steel bracket was used to fix the distance between hydrophones. The bracket was made from a stainless cylinder-shaped bar with a cross structure as its backbone (bar diameter: $2.5 \mathrm{~cm}$ ) and a reinforced stainless bar (bar diameter: $2 \mathrm{~cm}$ ) at each quadrant (Fig.2). A $5 \mathrm{~cm}$ extending bar (bar diameter: $0.3 \mathrm{~cm}$ ) was affixed perpendicularly to the bracket plane at the center and end of each arms to mount the hydrophones, to minimize the interference of the bar to the sound (including reflection and/or shadowing) (Fig.2). Inter-hydrophone distance along the backbone structure of the bracket was $1.47 \mathrm{~m}$ in PRE and $1.54 \mathrm{~m}$ in BG.

During the sound recording, the hydrophone arrays were deployed from the side of the boat so that the plate was in the horizontal plane at a depth of $1 \mathrm{~m}$. Floats and attached weights limited array movement to reduce noise due to water flow (Fig.2). The acoustic data were stored directly on the hard drive of a computer in technical data management streaming (TDMS) format and sampled at a rate of either 200 
$173 \mathrm{kHz}$ or $512.828 \mathrm{kHz}$, giving a Nyquist frequency of $100 \mathrm{kHz}$ and $256.414 \mathrm{kHz}$, respectively. The

174 presence of signals was monitored in real-time by using both the PC screen for waveforms monitoring and

175 a headphone connected to the center hydrophone. To minimize the chance of missing good signal, a three

176 second pre-recording buffer was employed. Upon detecting a signal, a manual trigger was used to

177 initiated a recording with the buffer included.

178 The Reson hydrophones were calibrated prior to shipment from the factory (S1 Fig.). The remaining components of the recording system, including the amplifier, filter, A/D converter and laptops, were calibrated in the lab prior to the field survey by inputting a calibration signal generated by an OKI underwater sound level meter (model SW1020; OKI Electric Industry Co., LTD., Tokyo, Japan). Signal

flow was also simultaneously monitored with an oscilloscope (model TDS1002C; Tektronix Inc.,

Beaverton, OR, USA). The noise floor of the recording system was about 65 and $55 \mathrm{~dB} \mathrm{re} 1 \mu \mathrm{Pa}^{2} / \mathrm{Hz}$ at $100 \mathrm{~Hz}$ and $1 \mathrm{kHz}$, respectively, and flat at about $50 \mathrm{~dB}$ re $1 \mu \mathrm{Pa}^{2} / \mathrm{Hz}$ between $10 \mathrm{kHz}$ and $100 \mathrm{kHz}$, which were lower than the ambient noise level at sea state 0 in our study (S1 Fig.), and suitable for noise monitoring.

\section{Sound propagation modeling} the signal propagation in a direct path. Following standard sound propagation theory (Au \& Hastings 2008; Aubauer et al. 2000; Urick 1983), a custom-compiled sound propagation model (S1 File) targeted on the impact of multi-path propagation on the original signals and took into account the hydrophone- 
193 site specific environment and bathymetry characteristics (such as water depth and bottom sediment 194 contents) was adopted for this study (Fig.3).

195 Since the energy flux density $\left(E F D, \mathrm{~dB}\right.$ re $\left.1 \mu \mathrm{Pa}^{2} \mathrm{~s}\right)$ is more meaningful in situations where considerable 196 signal distortion occurs during propagation (Urick 1983), the estimated transmission loss (TL) for each location was subsequently derived from the difference from the energy flux density of the received signal

$$
T L=E F D_{r}-E F D_{s}
$$

$$
E F D=10 \times \log _{10}\left\{\int_{0}^{T}\left(p^{2}(t) / p_{\text {refl }}^{2}\right) d t\right\}
$$

Where $p(t)$ is the sound pressure in $\mu \mathrm{Pa}$, then $p_{\text {ref } 1}$ was $1 \mu \mathrm{Pa}^{2} \mathrm{~s}$. For each hydrophone and animal depth

environment-dependent transmission loss coefficient by the equation:

$$
T L=k \times \log _{10}\left(r / r_{0}\right)
$$

Where $k$ was the transmission loss coefficient, $r$ was the distance between the animal and hydrophone,

\section{Acoustic data analysis}


for further analyzing.

\section{3} recording of signal input from all hydrophones. Signal waveforms from the different recording channels

\section{Acoustic localization}

Passive acoustic localization of vocalizing animals based on differences in the time of arrival of the same sound between all pairs of hydrophone receivers is a well-established technique (Au \& Benoit-Bird 2003; Janik 2000b; Jensen et al. 2009a; Spiesberger 1997; Spiesberger \& Fristrup 1990; Wahlberg et al. 2001; Watkins \& Schevill 1972). In this study, a custom-written package based on Matlab software (version R2010b; The Mathworks, Inc., Natick, MA, USA), named TOADY (King et al. 2014; Quick \& Janik 2008; Quick \& Janik 2012; Quick et al. 2008; Schulz et al. 2006; Schulz et al. 2008) was adopted for localizing phonating animals. The time delays were preserved on the simultaneous multi-track 
233 Before cross-correlation processing, a digital high-pass filter set to start rolling off just below the

234 minimum frequency of the fundamental frequency contour of each whistle was used to eliminate any low-

235 frequency background noise interference. The position of the largest peak in the resulting cross-

236 correlation vector represents the amount by which the two signals are offset in time (Hayes et al. 2000).

237 Signals with more than one equivalent peak and/or low cross-correlation maxima were discarded

238 (Lammers \& Au 2003). The time delays were used to generate hyperboloid surfaces of possible source

239 locations.

240 The standard hyperboloid can be estimated by rotating a standard hyperbola along its transverse axis. In

241 detail, the standard hyperbola can be constructed by equations:

$242 \quad x^{2} / a_{i j}^{2}-y^{2} / b_{i j}^{2}=1$

243

$a_{i j}=c \times t_{i-j} / 2$

$d_{i j}=\sqrt{\left(x_{i}-x_{j}\right)^{2}+\left(y_{i}-y_{j}\right)^{2}+\left(z_{i}-z_{j}\right)^{2}}$

245

$b_{i j}=\sqrt{\left(d_{i j} / 2\right)^{2}-a_{i j}^{2}}$

246 Where $(x, y)$ represent the locus coordinates in two dimensions at the hyperbola located alone the

247 hydrophone array plane, $a_{i j}$ and $b_{i j}$ represent the distance from the center to either vertex and the length of

248 a segment perpendicular to the transverse axis drawn from each vertex to the asymptotes of the hyperbola

249 between the hydrophone $\mathrm{i}$ and $\mathrm{j}$, respectively. The symbols $\left(x_{i}, y_{i}, z_{i}\right)$ and $\left(x_{j}, y_{j}, z_{j}\right)$ represent the three-

250 dimension coordinates of the hydrophone $i$ and $j$, respectively, $c$ represents the speed of sound in water in

$251 \mathrm{~m} / \mathrm{s}$, and $t_{i-j}$ represents the time delay between the hydrophones $i$ and $j$ in seconds. The maximum

252 allowable time delay between a pair of hydrophones in the array is limited to the direct-path propagation 
253 time between them (Helble et al. 2015) as:

$254 \max \left(t_{i-j}\right)=d_{i j} / c$

255 Where $d_{i j}$ represent the separation of the hydrophone $i$ and $j$ in $\mathrm{m}$. The standard hyperboloid was then

256

257

258

259

260

261

262

263

264

265

266

267

268

269

270

271

272 rotated and further recast to the center of the spatial geometry of the corresponding array-pair positions.

Once all the hyperboloids were established, contours of the hyperboloids (hyperbolae) at varied assumed animal depths, ranging from the water surface to the bottom set at $0.5 \mathrm{~m}$ increments, were displayed in the graphical interface of the TOADY software for visual inspection the hyperbolic fixing (Fig.5C). Four hydrophones resulted in six hyperbolae and yield four points of intersection (for each independent combination of a hydrophone triad, only two of the three time differences were linearly independent, and all three hyperbolae intersected at a single point) (Laurinolli et al. 2003). The localization accuracy was increased by inclusion of the depth function (Quick et al. 2008), and animal depth was estimated as that where the surface area of the polygon formed by the hyperbola intersections was minimum (Quick et al. 2008). The average of the hyperboloid intersections was taken as the best estimate of the sound source's location (Clark \& Ellison 2000; Laurinolli et al. 2003; Schulz et al. 2006;

Schulz et al. 2008).

Ideally, all the four intersections occurred at one point (Fig.5C). The location error was assessed by a linear error propagation model (Taylor 1997), and the root-mean-square (rms) location error was estimated using the equation:

$\varepsilon_{r m s}=\sqrt{\varepsilon_{x}^{2}+\varepsilon_{y}^{2}+\varepsilon_{z}^{2}}$

Where $\varepsilon_{x}, \varepsilon_{y}$, and $\varepsilon_{z}$ are the standard deviation (SD) of the hyperbolae intersections in the zonal, 
273 meridional, and vertical directions, respectively (Laurinolli et al. 2003; Schulz et al. 2008; Wahlberg et al.

274 2001).

\section{Signal extraction}

276 Whistles with successful source location estimates were extracted for sound parameter analysis using

277 the center hydrophone channel. The extracted whistle was assigned to one of the following six tonal types

278 based on its fundamental time-frequency contour as: flat, down, rise, U-shape, concave and sine. All tonal

279 types were mutually exclusive (Fig. 6, for detailed definition, see Wang et al. 2013). A three-step

280 procedure was applied to extract the candidate whistles (Fig. 7). A 2-s signal was extracted for each

281 candidate whistle (the whole signal in Fig.7A and B). The actual whistle was subsequently measured from

282 the start and end points of the fundamental contour (Fig. 7C) and further extracted it as the portion

283 containing $98 \%$ of the total cumulative energy, which started at the time when $1 \%$ of the cumulative

284 signal energy was reached ( $t_{1 \% c e}$, in Fig.7E) and ended when $99 \%$ of the cumulative signal energy was

285 reached $\left(\mathrm{t}_{99 \% \mathrm{ce}}\right.$, in Fig.7E). Whistle duration was derived from the time difference between the $1^{\text {st }}$ and $99^{\text {th }}$

286 cumulative energy percentiles (in Fig.7E). A $500 \mathrm{~ms}$ ambient noise selection was extracted either before

287 of after (in Fig.7B) each whistle from the 2-s signal, with a gap of over $0.2 \mathrm{~ms}$ from either sides of the

288 whistle fundamental contour (in Fig.7B). All spectrograms were computed with 25 ms Hann windows

289 (5000 and 12820 samples, zero-padded to 8192 and 16384 samples for sampling frequencies of 200 and

$290512 \mathrm{kHz}$, respectively) for FFT computation with $80 \%$ overlap for a temporal resolution of $5 \mathrm{~ms}$ and an

291 interpolated spectral frequency resolution of 24.4 and $31.1 \mathrm{~Hz}$, respectively.

\section{Apparent source levels and source energy flux density}


where $p(t)$ was the sound pressure in $\mu \mathrm{Pa}$, and $p_{\text {ref } 2}$ was $1 \mu \mathrm{Pa} . S P L_{r m s}$ critically relies upon the signal

\section{Power spectral density and One-third octave band levels}

311 Power spectral density ( $\mathrm{dB}$ re $1 \mu \mathrm{Pa}^{2} \mathrm{~Hz}^{-1}$ ), the averaged sound power in each $1 \mathrm{~Hz}$ band (Sims et al.

312 2012b) were calculated using Welch approach for each whistle over its $98 \%$ energy windows and their 
313

314

315

316

317

318

319

corresponding noise to assess the detailed acoustic energy distribution. Their one-third octave band levels

( $\mathrm{dB}$ re $1 \mu \mathrm{Pa}^{2}$ ) were further calculated to assess how cetaceans auditory systems perceive sound and were impacted by ambient noise (Madsen et al. 2006). All power spectral density and one-third octave band levels were computed with $0.2 \mathrm{~s}$ slice window, with $95 \%$ overlap between two slices for FFT computation, resulting in an interpolated spectral frequency resolution of 3.05 and $3.91 \mathrm{~Hz}$ for sampling frequencies of 200 and $512 \mathrm{kHz}$, respectively.

\section{Active communication space}

Detection of a tonal signal against a continuous broad-band noise background will be effectively masked by only a relatively narrow band of frequencies centered on the tonal stimulus, namely the critical bandwidth (Fletcher 1940). The critical ratio is another measure of auditory filter width and an indirect method for estimating critical bandwidth ( $\mathrm{Au} \&$ Moore 1990). At the detection threshold, the signal power equals the noise power, so that the auditory filter width is the ratio of the threshold intensity of a tone over the ambient noise power spectral density at the frequency in question (Fletcher 1940).

The active communication space is a combined function of the signal source level, the dolphin auditory threshold, the habitat-specific transmission loss, and the masking level at the one third octave band center frequency in question (Janik 2000a; Jensen et al. 2012; Quintana-Rizzo et al. 2006). The masking level is determined by the noise one-third octave band level or the masked tone threshold, whichever dominated.

The masked tone threshold is the sum of the noise power spectral density and the critical ratio at the frequency in question (Janik 2000a; Jensen et al. 2012; Quintana-Rizzo et al. 2006). The active communication space of each whistle is estimated as the maximum range at which the signal can still be 
333

334

335

336

337

338

339

340

341

342

343

344

345

346

347

detected in at least one of the one-third octave bands analyzed after accounting for the transmission loss

(Miller 2006). For whistle signals, the one-third octave band that determines the maximum range is always at the peak frequency of the signal one-third octave band levels (Fig.8).

The active communication space for each whistle can be modeled by the equations:

$k \times \log _{10}[\operatorname{mean}(\mathrm{ACS})]=\mathrm{TL}=\left[\operatorname{mean}\left(\operatorname{Sig} \_\mathrm{TOBL}\right)\right](f p)-\max \{\mathrm{ML}(f p), \mathrm{AT}(f p)\}$

$k \times \log _{10}[\max (\mathrm{ACS})]=\mathrm{TL}=\left[\max \left(\operatorname{Sig} \_\mathrm{TOBL}\right)\right](f p)-\max \{\mathrm{ML}(f p), \mathrm{AT}(f p)\}$

$\operatorname{ML}(f p)=\max \{[$ mean $($ Noi_TOBL $)](f p), \operatorname{MTT}(f p)\}$

$\operatorname{MTT}(f p)=[$ mean $($ Noi_PSD $)](f p)+\mathrm{CR}(f p)$

Where ACS was the active communication space of the whistle in the near simultaneous ambient noise conditions obtained from the matched noise sample, mean(Sig_TOBL) and $\max \left(\operatorname{Sig}_{-} \mathrm{TOBL}\right)$ were the averaged and maximum one-third octave band level for all the $200 \mathrm{~ms}$ slices for each whistle, $f_{p}$ was determined by the peak frequency of the averaged one-third octave band levels for all the $200 \mathrm{~ms}$ slices for each whistle, mean(Noi_PSD) and mean(Noi_TOBL) were the averaged power spectral density and one-third octave band levels of all the $200 \mathrm{~ms}$ slices from the matched noise sample for each whistle, ML was the masking level, MTT was the masked tone threshold, and AT was Sousa auditory threshold. The Sousa audiogram with a frequency span of $500 \mathrm{~Hz}$ to $38 \mathrm{kHz}$ (which cover the fundamental contour range of Sousa whistles of $520 \mathrm{~Hz}$ to $33 \mathrm{kHz}$ (Wang et al. 2013)) was estimated by fitting a third-order polynomial curve to the auditory thresholds between $5 \mathrm{kHz}$ and $38 \mathrm{kHz}$ (Li et al. 2012). CR was the dolphin critical ratio (Johnson et al. 1989), and was obtained by following the equation:

$$
\mathrm{CR}=19.8+0.075 \times f^{1 / 2}
$$


353 Where $\mathrm{CR}$ was in $\mathrm{dB}$ and $f$ was the frequency in $\mathrm{Hz}$. The equation was obtained by applying a least-

354 square fit to the bottlenose dolphin critical ratio data (Johnson 1968a; Moore \& Au 1982)

355 In cases where the masking level was always higher than the relevant Sousa auditory threshold, i.e., the

356 active communication space was noise-limited, the theoretical active communication space determined by

357 the Sousa auditory threshold alone was also calculated. The active communication space determined by

358 auditory threshold alone $\left(A C S_{a t}\right)$ can be modeled as:

359

$k \times \log _{10}\left[\right.$ mean $\left.\left(\mathrm{ACS}_{\mathrm{at}}\right)\right]=\mathrm{TL}=\left[\operatorname{mean}\left(\operatorname{Sig} \_\mathrm{TOBL}\right)\right](f p)-\mathrm{AT}(f p)$

360

$k \times \log _{10}\left[\max \left(\mathrm{ACS}_{\mathrm{at}}\right)\right]=\mathrm{TL}=\left[\max \left(\operatorname{Sig} \_\mathrm{TOBL}\right)\right](f p)-\mathrm{AT}(f p)$

\section{Statistical analysis}

362 Descriptive statistics of all measured acoustic parameters were obtained and presented in the form of

363

364

365

366

367

mean, $\mathrm{SD}$, and ranges if they were normal distributed. For those parameters with a grossly skewed distribution, descriptive parameters of median, quartile deviation (QD), 5 percentile (P5), and 95 percentile (P95) were adopted. The Levene's test for equality of error variances and KolmogorovSmirnov goodness-of-fit test were used to analyze homogeneity of variance and the distributions of the data, respectively. Nonparametric statistical analyses (Zar 1999) were adopted if data were not normally distributed. The Kruskal-Wallis test (Zar 1999) was used to examine the difference in the mean of the transmission loss coefficient of different test signals running in the sound propagation model. The MannWhitney $U$-test (Zar 1999) was used to analyze differences between transmission loss coefficients, as well as acoustic parameters between sites. Differences in apparent source levels and energy flux density across different whistle tonal types was analyzed by the Kruskal-Wallis test (Zar 1999), and Duncan's multiple 
373

374

375

376

377

378

379

380

381

382

383

384

385

386

387

comparison test (Zar 1999) was used for post hoc comparisons of acoustic parameter among tonal types.

Statistical analyses were performed using SPSS 16.0 for Windows (SPSS Inc., Chicago, U.S.A.).

Differences were considered significant at $p<0.05$.

\section{Ethical statement}

Permission to conduct the study was granted by the Ministry of Science and Technology of the People's Republic of China. The research permit was issued to the Institute of Hydrobiology of the Chinese Academy of Sciences (Permit number: 2011BAG07B05).

\section{Results}

Six hundred and thirty four whistles were recorded during 14 observation days, from which 33 whistles were successfully selected from two days in the Pearl River Estuary and 209 whistles from eight days in the Beibu Gulf (Table 1) for further analysis.

\section{Sound propagation modeling}

Sixteen whistles with estimated source distance from one of the 5 hydrophone channels close to $1 \mathrm{~m}$ were selected as a proxy for whistle sources and imported to the sound propagation model. The sound propagation speed in water $\left(c_{w}\right)$ was calculated as $1538 \mathrm{~m} / \mathrm{s}$ and $1535 \mathrm{~m} / \mathrm{s}$, for the Pearl River Estuary and Beibu Gulf, respectively, according to the Medwin equation (Medwin 1975) based on the average measured site-specific temperature, salinity, and water depth (Table 2). The sound speed in air $\left(c_{s}\right)$ was $343 \mathrm{~m} / \mathrm{s}$, and in bottom sediment $\left(c_{b}\right)$ was 1535 and $1742 \mathrm{~m} / \mathrm{s}$ for Pearl River Estuary and Beibu Gulf, respectively. The impedances $z_{s}$ and $z_{w}$ were 400 and $1.54 \times 10^{6} \mathrm{Pam}^{-1} \mathrm{~s}, \mathrm{z}_{\mathrm{b}}$ was $2.19 \times 10^{6}$ and $3.45 \times 10^{6}$ 
393 Pam $^{-1}$ s for Pearl River Estuary and Beibu Gulf, respectively (Urick 1983), since the sediment types were

394 different, with clay silt in Pearl River Estuary and fine sand in Beibu Gulf (TQ Zeng and HW Su,

395 personal communications). The hydrophone depth was set at $1 \mathrm{~m}$ to mirror the real hydrophone setup

396 during sound recording. The water depth in Pearl River Estuary and Beibu Gulf was set as a range from 5

$397 \mathrm{~m}$ to $9 \mathrm{~m}$ and from $2 \mathrm{~m}$ to $8 \mathrm{~m}$, respectively, to mirror the measured site-specific depth (Table 2). The

398 maximum distance between animal and hydrophone was set at $50 \mathrm{~m}$ (Fig. 4), corresponding to the

399 maximum localized whistle distance of $49.6 \mathrm{~m}$ (see next paragraph). The reflective coefficients at the air-

400 water interface were averaged at -0.09 for both of the Pearl River Estuary and Beibu Gulf, whereas the

401 reflective coefficients at the water-bottom interface were averaged at 0.24 and 0.46 for Pearl River Estuary

402 and Beibu Gulf, respectively. No significant difference in the mean transmission loss coefficient $k$ was

403 observed among different testing signals within each site (Pearl River Estuary: Kruskal-Wallis $\chi^{2}=16.82$,

$404 \mathrm{df}=15, p=0.33$; Beibu Gulf: Kruskal-Wallis $\chi^{2}=5.02, \mathrm{df}=15, p=0.91$ ). Thus, we pooled all test

405 signals within the sites to calculate average transmission loss. From the pooled data we estimated an

406 average $k$ in Pearl River Estuary of $-17.3 \pm 1.0$ [95\% CI (-17.4:-17.2)], which was significantly different

407 from that in Beibu Gulf of $-14.6 \pm 0.8$ [95\% CI (-14.7:-14.5)] (Mann-Whitney U-test: $\mathrm{z}=1532$, df $=1119$,

$408 p<0.01)$ (Fig.9).

409 Acoustic localization

410 Of all the analyzed whistles, the average estimated distance between the center hydrophone and 411 phonating animals was $6.8 \pm 4.2(\mathrm{SD}) \mathrm{m}$ (range: $2.1-23.8 \mathrm{~m}$ ) in Pearl River Estuary and $8.4 \pm 7.0(\mathrm{SD}) \mathrm{m}$

412 (range: 2.2-49.6 m) in Beibu Gulf (note that the distribution of the distance between hydrophone and 
413 phonating animal may vary if a different hydrophone was chosen). The average localization error $\left(\varepsilon_{r m s}\right)$

414 was $0.3 \pm 0.2 \mathrm{~m}$ and $0.5 \pm 0.4 \mathrm{~m}$ in Pearl River Estuary and Beibu Gulf, respectively.

\section{Apparent source levels and source energy flux density}

416 Significant differences in whistle duration was observed between Pearl River Estuary (mean \pm SD: 0.50

$417 \pm 0.19 \mathrm{~s}$ ) and Beibu Gulf (mean \pm SD: $0.44 \pm 0.20 \mathrm{~s}$ ) (Mann-Whitney $U$ test, $\mathrm{z}=-2.0, \mathrm{df}=241, p=0.04)$

418 (Table 3). On the other hand, no significant differences were found in all the measured apparent source

419 levels and source energy flux density between Pearl River Estuary and Beibu Gulf (Mann-Whitney U test,

$420 p<0.05$ ) (Table 3), thus they were pooled according to tonal classes for further analysis.

The 242 successfully located whistles consisted of 66 flat, 28 down, 28 rise, 64 U-shape, 15 convex,

422

423

424

425

426

427

428

429

430

431

432

and 41 sine whistles (Table 1). Significant differences were observed in the whistle duration, apparent

source levels, and source energy flux density among the six tonal types (whistle duration: Kruskal-Wallis

$\chi^{2}=29.27, \mathrm{df}=5, p<0.01 ; A S L_{r m s}:$ Kruskal-Wallis $\chi^{2}=17.02, \mathrm{df}=5, p<0.01 ; A S L_{r m s 200}:$ Kruskal-Wallis

$\chi^{2}=12.08, \mathrm{df}=5, p=0.03$ and source energy flux density: Kruskal-Wallis $\left.\chi^{2}=11.16, \mathrm{df}=5, p=0.04\right)$.

In detail, the duration of sine whistles (mean $\pm \mathrm{SD}: 0.60 \pm 0.3 \mathrm{~s}$ ) was significantly longer than flat (mean

$\pm \mathrm{SD}: 0.43 \pm 0.2 \mathrm{~s}$ ), rise (mean $\pm \mathrm{SD}: 0.43 \pm 0.2 \mathrm{~s}$ ) (Duncan's multiple-comparison test; $p<0.05$ ) and U-

shape (mean $\pm \mathrm{SD}: 0.39 \pm 0.2 \mathrm{~s}$ ) whistle types (Duncan's multiple-comparison test; $p<0.01$ ). Sine whistles had significantly lower $A S L_{r m s 200}$ and source energy flux density (Duncan's multiple-comparison test; $p<0.05$ ) and $A S L_{r m s}$ (Duncan's multiple-comparison test; $p<0.01$ ) than down whistles (Fig.10).

\section{One-third octave band levels}

The average peak frequency across the one-third octave band levels for all the $200 \mathrm{~ms}$ whistles slices 
433 across all whistles was $4.9 \pm 1.0 \mathrm{kHz}$ and $6.1 \pm 2.6 \mathrm{kHz}$ for Pearl River Estuary and Beibu Gulf,

434 respectively, which were significantly different (Mann-Whitney $\mathrm{U}$ test, $\mathrm{z}=-3.0, \mathrm{df}=241, p<0.01$ ) (Table

435 3). No significant difference was observed in the ambient noise sound pressure levels between Pearl River

436 Estuary $\left(S P L_{n o i}\right.$; mean $\left.\pm \mathrm{SD}: 122.3 \pm 5.0 \mathrm{~dB}\right)$ and Beibu Gulf (mean $\left.\pm \mathrm{SD}: 122.2 \pm 6.3 \mathrm{~dB}\right)$ (Mann-

437 Whitney $\mathrm{U}$ test, $\mathrm{z}=-1.0, \mathrm{df}=241, p=0.32$ ) (Table 3). However, their one third octave band noise level

438 property was significantly varied: in Pearl River Estuary, the one third octave band level at frequency

439 band of $4.47-5.63 \mathrm{kHz}$ (centered at $6.3 \mathrm{kHz}$ and corresponding to the peak frequency of whistles in Beibu

440 Gulf) was significantly higher than the band of $5.63-7.08 \mathrm{kHz}$ (centered at $5 \mathrm{kHz}$ and corresponding to the

441 peak frequency of whistles in Pearl River Estuary) (mean $\pm \mathrm{SD}: 95.8 \pm 3.2 \mathrm{~dB}$ and $97.1 \pm 4.2 \mathrm{~dB}$,

442 respectively; Wilcoxon signed ranks test, $\mathrm{Z}=-4.99, \mathrm{p}<0.001, \mathrm{~N}=33$ ), whereas, an opposite trend was

443 observed in Beibu Gulf (mean \pm SD: $99.3 \pm 4.3 \mathrm{~dB}$ and $96.9 \pm 4.2 \mathrm{~dB}$, respectively, for the two frequency

444 bands; Wilcoxon signed ranks test, $\mathrm{Z}=-8.59, \mathrm{p}<0.001, \mathrm{~N}=209$ ). In addition, the one third octave level

445 at frequency band of $4.47-5.63 \mathrm{kHz}$ in Pearl River Estuary was significantly higher than that in Beibu

446 Gulf (Mann-Whitney U-test: $\mathrm{z}=-4.02, \mathrm{df}=241, p<0.001$ ), although no significant difference in the

447 frequency band of 5.63-7.08 kHz was observed between them (Mann-Whitney U-test: $\mathrm{z}=-1.68, \mathrm{df}=241$, $448 \quad p=0.09)$.

\section{Active Communication space}

450 We calculated the mean and maximum active communication spaces across the $200 \mathrm{~ms}$ segments for 451 each analyzed whistle. The median of these results were $14.7 \pm 2.6 \mathrm{~m}$ and $17.1 \pm 3.5 \mathrm{~m}$, respectively, in

452 Pearl River Estuary, and $34.2 \pm 4.8 \mathrm{~m}$ and $43.5 \pm 4.6 \mathrm{~m}$, respectively, in Beibu Gulf. Both measures were 
453 significantly smaller in Pearl River Estuary than in Beibu Gulf (Mann-Whitney U test: $\mathrm{z}=-5.5$, df $=241$,

$454 p<0.01$ and $\mathrm{z}=-5.8, \mathrm{df}=241, p<0.01$, respectively). The largest mean active communication spaces for

455 any whistle in Pearl River Estuary and Beibu Gulf were estimated to be at $40.7 \mathrm{~m}$ and $209.7 \mathrm{~m}$,

456 respectively, while the largest maximum active communication spaces were estimated to be $51.1 \mathrm{~m}$ and

$457266.8 \mathrm{~m}$, respectively. Significant differences were observed in the mean and maximum active

458 communication space among six tonal types, which follow from the observed differences in apparent

459 source level (mean active communication space: Kruskal-Wallis $\chi^{2}=25.56$, df $=5, p<0.01$; maximum

460 active communication space: Kruskal-Wallis $\chi^{2}=23.80, \mathrm{df}=5, p<0.01$ ). In detail, both of the mean and

461 maximum active communication space of flat was significantly shorter than that in down and U-shape

462 (Duncan's multiple-comparison test; $p<0.01$ ). The mean active communication space of flat was

463 significantly short than that in rise (Duncan's multiple-comparison test; $p<0.01$ ). Of all the localized

464 whistles, the averaged one-third octave band levels of all matched $200 \mathrm{~ms}$ noise samples for each whistle

465 at the frequency determined by the peak frequency of the averaged one-third octave band levels of all the

466 whistle 200 ms slices ([mean(Noi_TOBL)](fp)) were significantly higher than Sousa auditory threshold at

467 the same frequency (AT(fp)) (Mann-Whitney $U$ test, $\mathrm{z}=-9.25, \mathrm{df}=241, p<0.01$ ), indicating that active

468 communication space was mainly noise-limited. However, 62 out of 242 whistles $(26.6 \%)$ with the

469 [mean(Noi_TOBL)](fp) lower than its corresponding AT(fp), indicating that their active communication

470 space were auditory-threshold limited, as opposed to noise-limited, we also estimated the theoretical

471 auditory-threshold-limited active communication space for all whistles. The theoretical mean auditory-

472 threshold limited active communication space in Pearl River Estuary (median \pm QD: $24.3 \pm 4.8 \mathrm{~m}$ ) was 
473 significantly shorter than that in Beibu Gulf (median \pm QD: $60.7 \pm 12.2 \mathrm{~m}$ ) (Mann-Whitney $\mathrm{U}$ test, $\mathrm{z}=$ -

$4744.2, \mathrm{df}=241, p<0.01)$, and the maximum was also significantly shorter in Pearl River Estuary (median \pm

475 QD: $35.7 \pm 4.6 \mathrm{~m}$ ) that in Beibu Gulf (median \pm QD: $74.3 \pm 25.3 \mathrm{~m}$ ) (Mann-Whitney $\mathrm{U}$ test, $\mathrm{z}=-4.4, \mathrm{df}=$

$476241, p<0.01$ ) (Table 3). The biggest mean auditory-threshold limited active communication space in

477 Pearl River Estuary and Beibu Gulf were estimated to be $106.5 \mathrm{~m}$ and $457.2 \mathrm{~m}$, respectively, whereas the

478 biggest maximum $\mathrm{ACS}_{\mathrm{at}}$ were estimated to be $109.3 \mathrm{~m}$ and $463.8 \mathrm{~m}$, respectively. Significant difference

479 was observed in the mean and maximum auditory-threshold limited active communication space among

480 six tonal types (Kruskal-Wallis $\chi^{2}=17.04, \mathrm{df}=5, \mathrm{p}<0.01$ and Kruskal-Wallis $\chi^{2}=15.28, \mathrm{df}=5, p<0.01$,

481 respectively). In detail, both of the mean and maximum auditory-threshold limited active communication

482 space of flat were significantly shorter than that in U-shape (Duncan's multiple-comparison test; $p<0.05$ ).

\section{Discussion}

out of 209) analyzed whistles in Beibu Gulf from 22 August, 2014 and 88\% (29 out of 33) analyzed

whistles in Pearl River Estuary from 5 June, 2014, the data within these days was obtained from many

different dolphin groups and participated in variety of activities. Thus, the analyzed data was

representative for the region where they were obtained.

\section{Sound propagation modeling}

491 Depending on local conditions, the spreading loss constant $k$ normally ranges from spherical spreading 
493 River Estuary (mean $\pm \mathrm{SD}$ : $-17.3 \pm 1.0$; range: from -20.5 to -15.5 ) followed an almost spherical

494 spreading model and was comparable to that calculated for shallow waters of Koombana Bay in Western

495 Australis of -18 , which was derived from playback experiments with variable receiver and sender

496 locations at an approximate homogenous water depth of 5-7 $\mathrm{m}$, using pure tone sounds with a frequency

497 span of 1-7 kHz (Jensen et al. 2012) and the empirical and theoretical derived transmission loss

498 coefficient at the Antarctic Peninsula of -17.8 (Širović et al. 2007). The transmission loss coefficient in

Beibu Gulf (mean \pm SD: $-14.6 \pm 0.8$; range: from -16.5 to -12.1 ) was equidistant between spherical and

cylindrical spreading. The range of the transmission loss coefficient estimated in Pearl River Estuary and

501

502

503

504

505

506

507

508

509

510

511

512

Beibu Gulf (Fig.9) was also comparable to that estimated with a water depth less than $3 \mathrm{~m}$ and in mud or sand sediment ( $\mathrm{k}$ range from -26.6 to -14.5$)$ and in channels with water depth between $3 \mathrm{~m}$ and $5.3 \mathrm{~m}(\mathrm{k}$ range from -24.5 to -12.8 ) in Sarasota Bay, Florida (Quintana-Rizzo et al. 2006). Therefore, our transmission loss estimates were well within the range of currently published findings in similar habitats.

\section{Acoustic localization}

The potential factors that influence the source location include ambient noise in the transmission paths, variability in sound speed in the media (Clark \& Ellison 2000; Tiemann et al. 2004), multipath arrivals of a signal at the hydrophone (Clark \& Ellison 2000; Hayes et al. 2000), and array configurations (Janik 2000a). However, we estimated low localization error in both of the Pearl River Estuary and Beibu Gulf, with error percentages $\left(\varepsilon_{r m s}\right.$ divided by mean localized distance between hydrophone and animal $\left.(r)\right)$ of $0.3 / 6.8=4.4 \%$ and $0.5 / 8.4=5.9 \%$, respectively. Therefore, error due to source localization was not expected to be large in our results. 
513 The low localization error in this study may be ascribed to the following counter error analysis

514 strategies, firstly, the use of waveform, rather than spectrogram cross-correlation technique. In order to 515 determine the time delay between two hydrophones, a cross-correlation function can be applied to either

516 signal waveforms or spectrograms (Janik 2000a). Compared with waveform cross-correlation, 517 spectrogram cross-correlation technique may introduce a slightly larger error (Clark \& Ellison 2000). The 518 error was due to the time grid spacing resolution during spectrogram calculation by averaging over small 519 time slices of the original signals (Janik 2000a). Secondly, the inclusion of the scanning depth function 520 (an extra dimension to the array plane) in the TOADY localization program in conjunction with the two 521 dimensional array recording systems makes possible the three dimensional localization of the animal and 522 helps to increase the accuracy of the localization (Quick et al. 2008), since using a two dimensional array 523 in a three dimensional environment may generate some errors (Janik 2000a). On the other hand, the 524 optimal source location in passive acoustic localization can be achieved when phonation animals inside 525 the array and the source-to-hydrophone distance of the same order of magnitude as inter-hydrophone 526 spacing (Madsen \& Wahlberg 2007). Additionally, source-to-array distance to a range of three to four 527 times the hydrophone array dimension can still be localized with high confidence (Watkins \& Schevill 528 1972). Of all the localized whistles in this study, those with a source-to-hydrophone distance smaller than $5293 \mathrm{~m}, 12 \mathrm{~m}$, and $15 \mathrm{~m}$, which mimics the distance of one time, three times, and four times of the maximum 530 inter-hydrophone spacing, account for $27.3 \%, 83.9 \%$ and $93.9 \%$, respectively. In addition, the $95 \%$ 531 confidence interval of the mean distance between the animal and hydrophone (Pearl River Estuary: 5.4$5328.3 \mathrm{~m}$, Beibu Gulf: 7.4-9.3 m) was well within three times of the maximum inter-hydrophone spacing. 
533 This also account for the high acoustic localization in this study.

\section{Apparent source level and noise levels}

535 The apparent source levels of Sousa whistle obtained in this study, with the $A S L_{r m s}$ over its $98 \%$ energy

536 window of $137.4 \pm 6.9 \mathrm{~dB}$ (range: 114.1-160.4 dB) and $A S L_{r m s}$ over 200 ms running windows of $139.5 \pm$

$5376.9 \mathrm{~dB}$ (range: $115.6-161.4 \mathrm{~dB}$ ), were similar to the estimated mean and range of the $A S L_{r m s}$ of Atlantic

538 spotted dolphin (Stenella frontalis) and bottlenose dolphin at Gulf of Mexico (Frankel et al. 2014), but

539 lower than those found for other dolphin species, including Hawaiian spinner dolphins (Stenella

540 longirostris) (Watkins \& Schevill 1974), common dolphin (Deiphinus delpliis) (Fish \& Turl 1976), white-

541 beaked dolphins (Rasmussen et al. 2006), baiji (Lipotes vexillifer) (Wang et al. 2006), short-

542 finned pilot whale (Globicephala macrorhynchus) (Fish \& Turl 1976) and killer whale (Orcinus orca)

543 (Miller 2006), and bottlenose dolphin(Fish \& Turl 1976; Janik 2000a; Jensen et al. 2012; Tyack 1985) in

544 other regions (Table 4). The observed no significant difference in broad band noise level between the two

545 regions in our study may be due to the fact that, in order to model the active communication range of

546 whistles in real time noise conditions, the analyzed noise were derived from sound file with whistle

547 recorded in good SNR and successfully localized. However, majority of good whistles were obtained

548 either far away from the construction or navigation region in Pearl River Estuary or without dolphin

549 tourism boat nearby in Beibu Gulf and represent an environment with less anthropogenic noise pollution.

550 Besides, the fact that the successfully localized whistles in this study were from a less anthropogenic

551 impacted environment may, in part, account for the low source level of the humpback dolphin whistles,

552 since dolphins may use higher amplitude sound in a noisy environment. Additionally, the frequency of 
553 dolphin whistles tend to modify according to environmental ambient noise, and the bottlenose dolphin

554 was observed to produced whistles with lower (Morisaka et al. 2005) or higher (May-Collado \& Wartzok

555 2008) frequencies at higher ambient noise conditions. In present study, both the averaged peak frequency

556 of whistles and one third octave band level of noise were significantly different between Pearl River

557 Estuary and Beibu Gulf. However, the reasons why humpback dolphins emitted whistles with peak

558 frequency coincidence with the noise one third octave frequency band with higher noise level in both of

559 these two regions deserve further investigation.

560 Active communication space

561 Active communication space has been estimated for bottlenose dolphins (Janik 2000a; Jensen et al.

562 2012; Quintana-Rizzo et al. 2006), killer whale (Miller 2006), white-beaked dolphins (Rasmussen et al.

563 2006) and baiji (Wang et al. 2006). In these studies, the whistle source levels used to model the active

564 communication space were either the highest and lowest source levels (Rasmussen et al. 2006), the mean

565 source level (Wang et al. 2006), the highest and mean source levels (Janik 2000a), the three

566 'representative' source levels (Quintana-Rizzo et al. 2006), the source level of each whistle over its 95\%

567 energy window (Jensen et al. 2012) or on the one-third octave band level scale (Miller 2006). The noise

568 condition was either extrapolated from literature at other habitats at sea-state 0 and sea-state 4 or 6 (Janik

569 2000a; Miller 2006), or using the noise level at the habitat in question under an optimal conditions of sea-

570 state 0-1 and without an adjacent boat (Jensen et al. 2012; Rasmussen et al. 2006), or under normal

571 recording conditions (Quintana-Rizzo et al. 2006; Wang et al. 2006). The propagation model was either

572 adopted from the spherical transmission attenuation model (Rasmussen et al. 2006; Wang et al. 2006), the 
573 Marsh and Schulkin shallow-water transmission model (Marsh \& Schulkin 1962) which assumes the

574 transducer and receiver were in the middle of the water column (Janik 2000a; Miller 2006) or derived by

575 the sound transmission experiment using playback signal of computer-generated whistle mimic tone at

576 varied distance with the transducer and receiver at a fixed depth of $1 \mathrm{~m}$ (Quintana-Rizzo et al. 2006), or

577 with varied transducer and receiver combination (Jensen et al. 2012). However, when using the signal

$578 A S L_{r m s}$ for modeling active communication space, the critical band theory of the mammalian auditory

579 system was not considered, and may therefore have integrated the energy from harmonics, which was the

580 integer times of the fundamental frequency and tends to be directional (Lammers \& Au 2003; Miller 2002;

581 Rasmussen et al. 2006), and more heavily affected by absorption. Additionally, the optimal or averaged

582 noise condition, rather than the real-time ambient noise level used for modeling active communication

583 space, may not shed much light for the biologically relevant active communication space of the signal.

584 This was further corroborated by the findings that the modeled active communication space of baiji

585 whistles with a $A S L_{r m s}$ of $143.2 \mathrm{~dB}$ will reduced from $6.6 \mathrm{~km}$ at normal noise level to a range of $22-220 \mathrm{~m}$

586 in a noisy boat traffic conditions. Furthermore, the Marsh and Schulkin model or playback experiment

587 with the transducer and receiver at a fixed depth may not represent the transmission loss pattern of the site,

588 because the sound transmission loss may vary within the water column (Quintana-Rizzo et al. 2006).

589 Transmission loss near the surface or the bottom of the water column was observed to be much higher

590 than that at the center of the water column (Janik 2000a). One-third of an octave approximates the

591 effective filter bandwidth of mammalian hearing systems (Fletcher 1940; Richardson et al. 1995). The

592 signal one-third octave band level information provided us with a starting point and an appropriate way 
593 for investigating how a mammal's auditory system perceives sound and the extent of the masking effect

594 of the ambient noise (Blackwell et al. 2004; Madsen et al. 2006). In this study, models integrating the

595 signal one-third octave band levels for each individual whistle, its corresponding real-time noise

596 conditions, and site-specific transmission attenuation were adopted to estimate the active communication

597 space in a more meaningful way. Notice should be addressed that, sound detection and discrimination

598 thresholds may differ, for example, in all the birds of budgerigars (Melopsittacus undulates), zebra

599 finches (Taeniopygia guttata) and canaries (Serinus canaria), the thresholds for discrimination between

600 calls of the same species was observed higher than the thresholds for detection of those calls (Lohr et al.

601 2003). The weakest portions of an emitted signal will always be lost during transmission before it is

602 detected by a receiver, but whether or not the transmitting animal can be discriminated by a receiving

603 animal will depend on how much of the information in the signal is needed to solve this task. Individual

604 discrimination information of bottlenose dolphins was encoded in the frequency modulation contour of

605 their signature whistles (Janik et al. 2006). Thus, the active communication space of signature whistles

606 was determined by the weakest portion of the signal modulation contour. However, whether signature

607 whistles also exist in humpback dolphins is still unknown and deserve further research. Since whistles

608 were narrowband signals, we believe that the active communication space calculated by using the

609 mean(Sig_TOBL), as obtained by a running average of all the one-third octave band levels for each

610 whistle over its $98 \%$ energy windows, will be similar to that based on the bandwidth of the entire whistle.

611 The small active communication space calculated in this study is a result of ambient noise limiting

612 detection ranges. The averaged one-third octave band noise levels were $98.7 \pm 4.5$ and $96.8 \pm 4.2 \mathrm{~dB}$ re 1 
$613 \mu \mathrm{Pa}$ at the band which accommodates the peak frequency of whistles at $4.9 \mathrm{kHz}$ and $6.1 \mathrm{kHz}$ for Pearl

614 River Estuary and Beibu Gulf, respectively. These results were almost $20 \mathrm{~dB}$ higher than the one-third

615 octave band noise levels at the same frequency band (estimated to be less than $75 \mathrm{~dB}$ ) for the estimation

616 of the whistle communication range of the white-beaked dolphins in Faxafloi Bay, Iceland (Rasmussen et

617 al. 2006), almost $30 \mathrm{~dB}$ higher than the ambient noise level (estimated to be $66.8 \mathrm{~dB}$ ) for the estimation of

618 the whistle communication range of baiji in the Shishou reserve (Wang et al. 2006), about 50 and $30 \mathrm{~dB}$

619 higher than the ambient noise level at sea state 0 and 4 respectively used for the estimation of the whistle

620 communication range of bottlenose dolphins at Moray Firth (Janik 2000a), and almost equal to the

621 background noise spectrum level plus critical ratios for the estimation of the whistle communication range

622 of bottlenose dolphins in Sarasota Bay (Quintana-Rizzo et al. 2006). The high ambient noise level

623 observed in both of the Pearl River Estuary and Beibu Gulf at less anthropogenic impacted areas may due

624 to the waves and biological noise, such as snap shrimps, and deserves further research.

625 The flourishing year round dolphin-watching industry makes the Beibu Gulf dominated by dolphin-

626 watching boats of about $7 \mathrm{~m}$ length and equipped with 40 horse power engine during the day time,

627 whereas the fast developing local economy makes Pearl-River Estuary dominated by different kinds of

628 hydrofoil ferries between Hongkong, Zhuhai, and Macao throughout the day, with the ferry length of

629 27.4-47.5 $\mathrm{m}$ and speed of 28-45 knots (Z-T Wang, unpublished data). Since different vessels tend to had

630 very different acoustic signatures(Hermannsen et al. 2014). The varied vessel traffic condition between

631 these two regions might also be a clue to the sources contributing to the ambient noise. Longtime noise

632 recordings will be needed for a better view of the soundscape difference between these two regions. 

and down. The significant difference in active communication space between flat and down, and between U-shape and rise may be due to their frequency band variations (Wang et al. 2013), since the active communication space was determined by the one-third octave band level at the whistle peak frequency and the corresponding noise one-third octave levels at the same frequency band. In addition, the significant differences in apparent source levels and its active communication space among different whistle tonal types may be associated with their different functions in different behavioral context. This was further corroborated by the findings that different whistle tonal classes were in relation with different especially cetaceans that rely heavily on acoustic for communication. The active communication space calculated in this study can be used for defining dolphin groups in a more biologically meaningful way during field surveys. As determined by the mean active communication range, humpback dolphins within contact and can be defined as the same dolphin group. In a more quieter environment, where dolphin auditory threshold determine the active communication range, animals which apart from each other at a 
653 During our field survey in Beibu Gulf, when fast moving dolphin-watching boat was presented even at a

654 distance of more than $1000 \mathrm{~m}$ away, the whistles recorded will be severely masked with the generated

655 vessel noise dominating the ambient noise. The negative impacts of vessel noise on cetacean have been

656 widely documented. The vessel noise recorded at the heavily ship-trafficked marine habitats in Denmark

657 from a range of different ship types was observed substantially elevated ambient noise levels across a

658 wide frequency band of $0.025-160 \mathrm{kHz}$ and can cause hearing range reduction of over $20 \mathrm{~dB}$ on harbor

659 porpoises (Phocoena phocoena) even at a distances of over $1 \mathrm{~km}$ away (Hermannsen et al. 2014). Small

660 vessels noise can significantly mask acoustically mediated communication in cetaceans and those

661 travelling at 5 knots in shallow waters of the Koombana Bay, Western Australia can reduce the

662 communication range of $26 \%$ on bottlenose dolphins within a distance of $50 \mathrm{~m}$ (Jensen et al. 2009a).

663 What's the impact of vessel traffic on local humpback dolphins, especially the hydrofoil ferries at heavy

664 shipping lanes of the PRE deserves further research.

665

666 Limitations

667 Cetacean audiograms can vary greatly among individuals of different age groups (Houser et al. 2008;

668 Popov et al. 2007), and the threshold may shift with the presence of masking noise (Johnson 1968a).

669 Therefore, the audiogram adopted in this study may not be considered representative of the auditory

670 sensitivity of Sousa as a whole, and more auditory studies covering different dolphin age groups are

671 needed for deriving an accurate audiogram of Sousa. The source level of dolphin whistles can vary

672 depending on the number, age, and sex of the individuals in a group, as well as their behavioral context 
673 (Fish \& Turl 1976; Frankel et al. 2014). The maximum apparent sound pressure level of $160.4 \mathrm{~dB}$ (rms)

674 observed here does not necessarily represent the capability of the species. Due to the trade-off between

675 high SNR and increased active space for high amplitude sound and decreased detection probability by

676 predator with low amplitude sound (Morisaka \& Connor 2007), dolphins might not produce whistles at

677 their maximum levels, even if rewarded in a conditioning procedure (Janik 2000a).

678 The directional pattern of outgoing signals and any directional hearing capability will impact the active communication range of animal vocalization ( $\mathrm{Au}$ 1993). Received sound pressure levels will be maximum when the phonating dolphin is pointed directly at the receiver, and vice verse. In this study,

both the directivity index $(D I)$ and the beam pattern $(B P)$ of the outgoing signal transmission and sound 1993):

$D I_{\text {receiving }}=16.94 \times \log _{10}(f)-14.69$

687 Where DI was directivity index, and $\mathrm{f}$ was frequency in $\mathrm{kHz}$. If this was also applicable and can be extrapolated for Sousa, then the directivity index for signals with frequencies lower than $7.37 \mathrm{kHz}$ will be close to 0 . 

model (S2 Fig), suggesting directionality would also have a minor effect on the results reported here. measurements.

\section{Conclusions and Implication of the findings} characteristics and on the impacts of noise on their biological functions. The present study backcalculated the apparent source levels of free-ranging Indo-Pacific humpback dolphin whistles in the shallow-water environments of Pearl River Estuary and Beibu Gulf, China, by using a 2 dimension crosstime ambient noise levels, masking tonal threshold, Sousa auditory threshold and site-specific 
713 with the acoustic signals of a wider range of marine fauna, the source level information of the dolphin

714 whistles can also be referenced as the safe biological ambient noise that an animal is exposed to and can

715 shed some light for evaluating the appropriate noise exposure level for humpback dolphin and regulation

716 or mitigation of underwater acoustic pollution. Furthermore, although biosonar clicks are easy to detect

717 automatically at close distance, and standard methods have been developed for passive acoustic

718 monitoring of biosonar clicks (Zimmer 2011), whistles may be detected at a greater range compared with

719 the biosonar clicks, which are higher in directionality and suffering higher transmission loss. The whistle

720 apparent source levels and site-specific transmission loss model derived in this study can aid in expanding

721 the application of passive acoustic monitoring strategies. These include the scope of local population

722 abundance estimation by incorporating the active detection range of the passive acoustic recorders(Wang

723 et al. 2014a), propagation characteristics of the environment, and animal vocalization rates (Frankel et al.

724 2014). Finally, the active communication space calculated in this study can be used to determine how far

725 apart members of dolphin group might be able to keep acoustic contact and be used for defining dolphin

726 groups in a more biologically meaningful way during field surveys. In addition, it can guide the

727 appropriate approach distance for local dolphin-watching boats and research boat during focal group

728 following.

730 Acknowledgments

731 The hydrophone array system was provided courtesy of the Public Technology Service Center, IHB,

732 CAS. We gratefully acknowledge the captains of Hongwei Su, Shaode Huang, Hongyu Su, Hongfang 
$733 \mathrm{Su}$, Yingqiang Li for their patience and cooperation, and Xiangxia Wu and Rui Zheng for logistic support.

734 Individual thanks are due to Wenjun Xu of the Ningbo No.2 High School of Zhejiang province for her

735 field and statistical assistance, Paul E. Nachtigall and Marc O. Lammers of the Hawaii Institute of Marine

736 Biology of the University of Hawaii for their helpful discussion about this study. Special thanks are also

737 extended to Susan Schmidt and the academic editor and many reviewers for their helpful critique of an

738 earlier version of this manuscript.

\section{References}

741

742

743

744

745

746

747

748

749

750

751

752

753

754

755

756

757

758

759

760

761

762

763

Acevedo-Gutiérrez A. 2002. Interactions between marine predators: dolphin food intake is related to number of sharks. Marine Ecology Progress Series 240:267-271.

Acevedo-Gutiérrez A, and Stienessen SC. 2004. Bottlenose dolphins (Tursiops truncatus) increase number of whistles when feeding. Aquatic Mammals 30:357-362.

Au WWL. 1993. The sonar of dolphins. New York: Springer-Verlag.

Au WWL, and Benoit-Bird KJ. 2003. Automatic gain control in the echolocation system of dolphins. Nature 423:861863.

Au WWL, and Hastings MC. 2008. Principles of marine bioacoustics New York: Springer Science.

$\mathrm{Au}$ WWL, and Moore PWB. 1990. Critical ratio and critical bandwidth for the Atlantic bottlenose dolphin. The Journal of the Acoustical Society of America 88:1635-1638. 10.1121/1.400323

Aubauer R, Lammers MO, and Au WW. 2000. One-hydrophone method of estimating distance and depth of phonating dolphins in shallow water. The Journal of the Acoustical Society of America 107:2744-2749.

Barco SG, Swingle WM, Mclellan WA, Harris RN, and Pabst D. 1999. Local abundance and distribution of bottlenose dolphins (Tursiops truncatus) in the nearshore waters of Virginia Beach, Virginia. Marine Mammal Science 15:394-408.

Blackwell SB, Lawson JW, and Williams MT. 2004. Tolerance by ringed seals (Phoca hispida) to impact pipe-driving and construction sounds at an oil production island. The Journal of the Acoustical Society of America 115:2346-2357.

Chen BY, Zheng DM, Yang G, Xu XR, and Zhou KY. 2009. Distribution and conservation of the Indo-Pacific humpback dolphin in China. Integrative Zoology 4:240-247. 10.1111/j.1749-4877.2009.00160.x

Chen T, Hung SK, Qiu YS, Jia XP, and Jefferson TA. 2010. Distribution, abundance, and individual movements of Indo-Pacific humpback dolphins (Sousa chinensis) in the Pearl River Estuary, China. Mammalia 74:117-125. 10.1515/Mamm.2010.024 
764

765

766

767

768

769

770

771

772

773

774

775

776

777

778

779

780

781

782

783

784

785

786

787

788

789

790

791

792

793

794

795

796

797

798

799

800

801

802
Clark CW, and Ellison WT. 2000. Calibration and comparison of the acoustic location methods used during the spring migration of the bowhead whale, Balaena mysticetus, off Pt. Barrow, Alaska, 1984-1993. The Journal of the Acoustical Society of America 107:3509-3517. 10.1121/1.429421

Clark CW, Ellison WT, Southall BL, Hatch L, Van Parijs SM, Frankel A, and Ponirakis D. 2009. Acoustic masking in marine ecosystems: intuitions, analysis, and implication. Marine Ecology Progress Series 395:201-222.

Connor RC, Smolker R, and Bejder L. 2006. Synchrony, social behaviour and alliance affiliation in Indian Ocean bottlenose dolphins, Tursiops aduncus. Animal Behaviour 72:1371-1378.

Davidson AD, Boyer AG, Kim H, Pompa-Mansilla S, Hamilton MJ, Costa DP, Ceballos G, and Brown JH. 2012. Drivers and hotspots of extinction risk in marine mammals. Proceedings of the National Academy of Sciences 109:3395-3400. 10.1073/pnas.1121469109

Fish JF, and Turl CW. 1976. Acoustic source levels of four species of small whales. San Diego, California: Naval undersea center. $\mathrm{p} 21$.

Fisher FH, and Simmons VP. 1977. Sound absorption in sea water. The Journal of the Acoustical Society of America 62:558-564. 10.1121/1.381574

Fletcher H. 1940. Auditory patterns. Reviews of modern physics 12:47-66.

Frankel AS, Zeddies D, Simard P, and Mann D. 2014. Whistle source levels of free-ranging bottlenose dolphins and Atlantic spotted dolphins in the Gulf of Mexico. The Journal of the Acoustical Society of America 135:16241631. 10.1121/1.4863304

Freitas M, Jensen FH, Tyne J, Bejder L, and Madsen PT. 2015. Echolocation parameters of Australian humpback dolphins (Sousa sahulensis) and Indo-Pacific bottlenose dolphins (Tursiops aduncus) in the wild. The Journal of the Acoustical Society of America 137:3033-3041. doi:http://dx.doi.org/10.1121/1.4921277

Hawkins E, and Gartside DF. 2009. Interactive behaviours of bottlenose dolphins (Tursiops aduncus) during encounters with vessels. Aquatic Mammals 35:259-268.

Hawkins ER, and Gartside DF. 2010. Whistle emissions of Indo-Pacific bottlenose dolphins (Tursiops aduncus) differ with group composition and surface behaviors. The Journal of the Acoustical Society of America 127:26522663

Hayes SA, Mellinger DK, Croll DA, Costa DP, and Borsani JF. 2000. An inexpensive passive acoustic system for recording and localizing wild animal sounds. The Journal of the Acoustical Society of America 107:35523555. 10.1121/1.429424

He Q, Bertness MD, Bruno JF, Li B, Chen G, Coverdale TC, Altieri AH, Bai J, Sun T, Pennings SC, Liu J, Ehrlich PR, and Cui B. 2014. Economic development and coastal ecosystem change in China. Scientific reports 4. 10.1038/srep05995

Helble TA, lerley GR, D'Spain GL, and Martin SW. 2015. Automated acoustic localization and call association for vocalizing humpback whales on the Navy's Pacific Missile Range Facility. The Journal of the Acoustical Society of America 137:11-21. 10.1121/1.4904505

Hermannsen L, Beedholm K, Tougaard J, and Madsen PT. 2014. High frequency components of ship noise in shallow water with a discussion of implications for harbor porpoises (Phocoena phocoena). The Journal of the Acoustical Society of America 136:1640-1653. doi:http://dx.doi.org/10.1121/1.4893908

Hoffman JM, Ponnampalam LS, Araújo CC, Wang JY, Kuit SH, and Hung SK. 2015. Comparison of Indo-Pacific 
803

804

805

806

807

808

809

810

811

812

813

814

815

816

817

818

819

820

821

822

823

824

825

826

827

828

829

830

831

832

833

834

835

836

837

838

839

840

841

humpback dolphin (Sousa chinensis) whistles from two areas of western Peninsular Malaysia. The Journal of the Acoustical Society of America 138:2829-2835. doi:http://dx.doi.org/10.1121/1.4934254

Houser DS, Gomez - Rubio A, and Finneran JJ. 2008. Evoked potential audiometry of 13 Pacific bottlenose dolphins (Tursiops truncatus gilli). Marine Mammal Science 24:28-41.

Janik VM. 2000a. Source levels and the estimated active space of bottlenose dolphin (Tursiops truncatus) whistles in the Moray Firth, Scotland. Journal of Comparative Physiology A-Sensory Neural and Behavioral Physiology 186:673-680.

Janik VM. 2000b. Whistle matching in wild bottlenose dolphins (Tursiops truncatus). Science 289:1355-1357.

Janik VM, Sayigh LS, and Wells RS. 2006. Signature whistle shape conveys identity information to bottlenose dolphins. Proceedings of the National Academy of Sciences of the United States of America 103:8293-8297. 10.1073/pnas.0509918103

Janik VM, and Slater PJ. 1998. Context-specific use suggests that bottlenose dolphin signature whistles are cohesion calls. Animal Behaviour 56:829-838.

Jefferson TA. 2000. Population biology of the Indo-Pacific hump-backed dolphin in Hong Kong waters. Wildlife monographs 144:1-65.

Jefferson TA, and Rosenbaum HC. 2014. Taxonomic revision of the humpback dolphins (Sousa spp.), and description of a new species from Australia. Marine Mammal Science 30:1494-1541. 10.1111/mms.12152

Jensen FH, Beedholm K, Wahlberg M, Bejder L, and Madsen PT. 2012. Estimated communication range and energetic cost of bottlenose dolphin whistles in a tropical habitat. The Journal of the Acoustical Society of America 131:582-592. 10.1121/1.3662067

Jensen FH, Bejder L, Wahlberg M, Aguilar De Soto N, Johnson MP, and Madsen PT. 2009a. Vessel noise effects on delphinid communication. Marine Ecology Progress Series 395:161-175.

Jensen FH, Bejder L, Wahlberg M, and Madsen PT. 2009b. Biosonar adjustments to target range of echolocating bottlenose dolphins (Tursiops sp.) in the wild. Journal of experimental biology 212:1078-1086. 10.1242/jeb.025619

Johnson CS. 1968a. Masked Tonal Thresholds in the Bottlenosed Porpoise. The Journal of the Acoustical Society of America 44:965-967. 10.1121/1.1911236

Johnson CS. 1968b. Relation between absolute threshold and duration of tone pulses in the bottlenosed porpoise. The Journal of the Acoustical Society of America 43:757-763. 10.1121/1.1910893

Johnson CS, McManus MW, and Skaar D. 1989. Masked tonal hearing thresholds in the beluga whale. The Journal of the Acoustical Society of America 85:2651-2654. 10.1121/1.397759

Kimura S, Akamatsu T, Fang L, Wang Z, Wang K, Wang D, and Yoda K. 2014. Apparent source level of free-ranging humpback dolphin, Sousa chinensis, in the South China Sea. Journal of the Marine Biological Association of the United Kingdom. 10.1017/S0025315414000071

King SL, Harley HE, and Janik VM. 2014. The role of signature whistle matching in bottlenose dolphins, Tursiops truncatus. Animal Behaviour 96:79-86. 10.1016/j.anbehav.2014.07.019

Lammers MO, and Au WWL. 2003. Directionality in the whistles of Hawallan Spinner Dolphins (Stenella longirostris): a signal feature to cue direction of movement? Marine Mammal Science 19:249-264.

Laurinolli MH, Hay AE, Desharnais F, and Taggart CT. 2003. Localization of North Atlantic right whale sounds in the 
842

843

844

845

846

847

848

849

850

851

852

853

854

855

856

857

858

859

860

861

862

863

864

865

866

867

868

869

870

871

872

873

874

875

876

877

878

879

880

Bay of Fundy using a sonobuoy array. Marine Mammal Science 19:708-723. 10.1111/j.17487692.2003.tb01126.x

Lewis J, Wartzok D, and Heithaus M. 2011. Highly dynamic fission-fusion species can exhibit leadership when traveling. Behavioral Ecology and Sociobiology 65:1061-1069. 10.1007/s00265-010-1113-y

Li S, Wang D, Wang K, Taylor EA, Cros E, Shi W, Wang Z, Fang L, Chen Y, and Kong F. 2012. Evoked-potential audiogram of an Indo-Pacific humpback dolphin (Sousa chinensis). The Journal of Experimental Biology 215: 3055-3063.

Lohr B, Wright TF, and Dooling RJ. 2003. Detection and discrimination of natural calls in masking noise by birds: estimating the active space of a signal. Animal Behaviour 65:763-777. 10.1006/anbe.2003.2093

Madsen P. 2005. Marine mammals and noise: Problems with root mean square sound pressure levels for transients. The Journal of the Acoustical Society of America 117:3952-3957.

Madsen PT, and Wahlberg M. 2007. Recording and quantification of ultrasonic echolocation clicks from freeranging toothed whales. Deep Sea Research Part I: Oceanographic Research Papers 54:1421-1444. 10.1016/j.dsr.2007.04.020

Madsen PT, Wahlberg M, Tougaard J, Lucke K, and Tyack PL. 2006. Wind turbine underwater noise and marine mammals: implications of current knowledge and data needs. Marine Ecology Progress Series 309:279295.

Marsh HW, and Schulkin M. 1962. Shallow - Water Transmission. The Journal of the Acoustical Society of America 34:863-864. 10.1121/1.1918212

Marten K, and Marler P. 1977. Sound transmission and its significance for animal vocalization. Behavioral Ecology and Sociobiology 2:271-290.

May-Collado L, and Wartzok D. 2008. A Comparison of Bottlenose Dolphin Whistles in the Atlantic Ocean: Factors Promoting Whistle Variation. Journal of Mammalogy 89:1229-1240.

Medwin H. 1975. Speed of sound in water: A simple equation for realistic parameters. The Journal of the Acoustical Society of America 58:1318-1319. 10.1121/1.380790

Miller P. 2002. Mixed-directionality of killer whale stereotyped calls: a direction of movement cue? Behavioral Ecology and Sociobiology 52:262-270. 10.1007/s00265-002-0508-9

Miller PJO. 2006. Diversity in sound pressure levels and estimated active space of resident killer whale vocalizations. Journal of Comparative Physiology a-Neuroethology Sensory Neural and Behavioral Physiology 192:449-459. 10.1067/s00359-005-0085-2

Moore PWB, and Au WWL. 1982. Masked pure - tone thresholds of the bottlenosed dolphin (Tursiops truncatus) at extended frequencies. The Journal of the Acoustical Society of America 72:S42. 10.1121/1.2019889

Morisaka T, and Connor RC. 2007. Predation by killer whales (Orcinus orca) and the evolution of whistle loss and narrow-band high frequency clicks in odontocetes. Journal of Evolutionary Biology 20:1439-1458. 10.1111/j.1420-9101.2007.01336.x

Morisaka T, Shinohara M, Nakahara F, and Akamatsu T. 2005. Effects of ambient noise on the whistles of IndoPacific bottlenose dolphin populations. Journal of Mammalogy 86:541-546.

$\mathrm{Ng} \mathrm{SL}$, and Leung S. 2003. Behavioral response of Indo-Pacific humpback dolphin (Sousa chinensis) to vessel traffic. Marine Environmental Research 56:555-567. 10.1016/S0141-1136(03)00041-2

PeerJ reviewing PDF | (2015:11:7848:1:1:NEW 26 Jan 2016) 
881

882

883

884

885

886

887

888

889

890

891

892

893

894

895

896

897

898

899

900

901

902

903

904

905

906

907

908

909

910

911

912

913

914

915

916

917

918

919

NRC. 2005. Marine mammal populations and ocean noise: determining when noise causes biologically significant effects. Washington, DC: National Research Council of the National Academies p135.

Pan W, Lindsay P, Wang Y, Qin D, Long Y, Jin T, Liang Z, Wang D, Su Y, and Pei Z. 2006. The importance of the IndoPacific humpback dolphin (Sousa chinesis) population of Sanniang Bay, Guangxi province, PR China: Recommendations for habitat protection. the 58th Annual Meeting of the International Whaling Commission. St. Kitts p1-6.

Plomp R, and Bouman MA. 1959. Relation between Hearing Threshold and Duration for Tone Pulses. The Journal of the Acoustical Society of America 31:749-758. 10.1121/1.1907781

Popov VV, Supin AY, Pletenko MG, Tarakanov MB, Klishin VO, Bulgakova TN, and Rosanova El. 2007. Audiogram variability in normal bottlenose dolphins (Tursiops truncatus). Aquatic Mammals 33:24-33.

Popper AN, and Hawkins A. 2012. The effects of noise on aquatic life. New York: Springer Science \& Business Media.

Preen A. 2004. Distribution, abundance and conservation status of dugongs and dolphins in the southern and western Arabian Gulf. Biological Conservation 118:205-218.

Quick NJ, and Janik VM. 2008. Whistle rates of wild bottlenose dolphins (Tursiops truncatus): Influences of group size and behavior. Journal of Comparative Psychology 122:305-311.

Quick NJ, and Janik VM. 2012. Bottlenose dolphins exchange signature whistles when meeting at sea. Proceedings of the Royal Society B: Biological Sciences 279:2539-2545.

Quick NJ, Rendell LE, and Janik VM. 2008. A mobile acoustic localization system for the study of free - ranging dolphins during focal follows. Marine Mammal Science 24:979-989.

Quintana-Rizzo E, Mann DA, and Wells RS. 2006. Estimated communication range of social sounds used by bottlenose dolphins (Tursiops truncatus). The Journal of the Acoustical Society of America 120:1671-1683. 10.1121/1.2226559

Rasmussen MH, Lammers M, Beedholm K, and Miller L. 2006. Source levels and harmonic content of whistles in white-beaked dolphins (Lagenorhynchus albirostris). The Journal of the Acoustical Society of America 120:510-517.

Reeves RR, Dalebout ML, Jefferson TA, Karczmarski L, Laidre K, O'Corry-Crowe G, Rojas-Bracho L, Secchi ER, Slooten E, Smith BD, Wang JY, and Zhou KY. 2008. Sousa chinensis. IUCN Red List of Threatened Species (Version 2015-6) (accessed 28 June 2015).

Richardson WJ, Greene CRJ, Malme Cl, and Thompson DH. 1995. Marine Mammals and Noise. San Diego: Academic Press

Schulz T, Whitehead H, and Rendell L. 2006. A remotely-piloted acoustic array for studying sperm whale vocal behaviour. Canadian Acoustics 34:54-55.

Schulz TM, Whitehead H, Gero S, and Rendell L. 2008. Overlapping and matching of codas in vocal interactions between sperm whales: insights into communication function. Animal Behaviour 76:1977-1988.

Sims PQ, Hung SK, and Wursig B. 2012a. High-Speed vessel noises in west Hong kong waters and their contributions relative to Indo-Pacific humpback dolphins (Sousa chinensis). Journal of Marine Biology 2012. 10.1155/2012/169103

Sims PQ, Vaughn R, Hung SK, and Wursig B. 2012b. Sounds of Indo-Pacific humpback dolphins (Sousa chinensis) in West Hong Kong: A preliminary description. The Journal of the Acoustical Society of America 131:EL48- 
920

921

922

923

924

925

926

927

928

929

930

931

932

933

934

935

936

937

938

939

940

941

942

943

944

945

946

947

948

949

950

951

952

953

954

955

956

957

958

EL53.

Širović A, Hildebrand JA, and Wiggins SM. 2007. Blue and fin whale call source levels and propagation range in the Southern Ocean. The Journal of the Acoustical Society of America 122:1208-1215. 10.1121/1.2749452

Smolker RA, Richards AF, Connor RC, and Pepper JW. 1992. Sex differences in patterns of association among Indian Ocean bottlenose dolphins. Behaviour 123:38-69.

Spiesberger JL. 1997. Passive acoustic localization enhanced with tomography and acoustic thermometry in the ocean. Marine and Freshwater Behaviour and Physiology 30:147-172. 10.1080/10236249709379022

Spiesberger JL, and Fristrup KM. 1990. Passive localization of calling animals and sensing of their acoustic environment using acoustic tomography. The american naturalist 135:107-153.

Surlykke A, Nachtigall PE, Fay RR, and Popper AN. 2014. Biosonar. New York: Springer.

Taylor JR. 1997. An introduction to error analysis: The study of uncertainties in physical measurements. Sausalito, CA: University Science Books.

Tervo OM, Christoffersen MF, Simon M, Miller LA, Jensen FH, Parks SE, and Madsen PT. 2012. High source levels and small active space of high-pitched song in bowhead whales (Balaena mysticetus). PLOS ONE 7:e52072.

Tiemann CO, Porter MB, and Frazer LN. 2004. Localization of marine mammals near Hawaii using an acoustic propagation model. The Journal of the Acoustical Society of America 115:2834-2843. 10.1121/1.1643368

Tyack P. 1985. An optical telemetry device to identify which dolphin produces a sound. The Journal of the Acoustical Society of America 78:1892-1895.

Urick RJ. 1983. Principles of underwater sound. New York: McGraw-Hill.

Wahlberg M, Møhl B, and Madsen PT. 2001. Estimating source position accuracy of a large-aperture hydrophone array for bioacoustics. The Journal of the Acoustical Society of America 109:397-406.

Wang JY, Yang SC, Fruet PF, Daura-Jorge FG, and Secchi ER. 2012. Mark-recapture analysis of the critically endangered eastern Taiwan Strait population of Indo-Pacific humpback dolphins (Sousa chinensis): Implications for conservation. Bulletin of Marine Science 88:885-902.

Wang K, Wang D, Akamatsu T, Fujita K, and Shiraki R. 2006. Estimated detection distance of a baiji's (Chinese river dolphin, Lipotes vexillifer) whistles using a passive acoustic survey method. Journal of the Acoustical Society of America 120:1361-1365. 10.1121/1.2221416

Wang Z-T, Akamatsu T, Wang K-X, and Wang D. 2014a. The Diel Rhythms of Biosonar Behavior in the Yangtze Finless Porpoise (Neophocaena asiaeorientalis asiaeorientalis) in the Port of the Yangtze River: The Correlation between Prey Availability and Boat Traffic. PLOS ONE 9:e97907. doi: 10.1371/journal.pone.0097907

Wang Z-T, Fang L, Shi W-J, Wang K-X, and Wang D. 2013. Whistle characteristics of free-ranging Indo-Pacific humpback dolphins (Sousa chinensis) in Sanniang Bay, China. The Journal of the Acoustical Society of America 133:2479-2489. doi: 10.1121/1.4794390

Wang Z-T, Nachtigall PE, Akamatsu T, Wang K-X, Wu Y-P, Liu J-C, Duan G-Q, Cao H-J, and Wang D. 2015. Passive acoustic monitoring the diel, lunar, seasonal and tidal patterns in the biosonar activity of the Indo-Pacific humpback dolphins (Sousa chinensis) in the Pearl River Estuary, China. PLOS ONE 10:e0141807. doi: 10.1371/journal.pone.0141807

Wang Z-T, Wu Y-P, Duan G-Q, Cao H-J, Liu J-C, Wang K-X, and Wang D. 2014b. Assessing the underwater acoustics 
959

960

961

962

963

964

965

966

967

968

969

970

971

972

973 of the world's largest vibration hammer (OCTA-KONG) and its potential effects on the Indo-Pacific humpbacked dolphin (Sousa chinensis). PLOS ONE 9:e110590. doi: 10.1371/journal.pone.0110590

Watkins WA, and Schevill WE. 1972. Sound source location by arrival-times on a non-rigid three-dimensional hydrophone array. Deep Sea Research and Oceanographic Abstracts: Elsevier. p 691-706.

Watkins WA, and Schevill WE. 1974. Listening to Hawaiian spinner porpoises, Stenella cf. longirostris, with a threedimensional hydrophone array. Journal of Mammalogy:319-328.

Xu X, Song J, Zhang Z, Li P, Yang G, and Zhou K. 2015. The world's second largest population of humpback dolphins in the waters of Zhanjiang deserves the highest conservation priority. Scientific reports 5. 10.1038/srep08147

Yeung YM, and Shen JF. 2008. The Pan-Pearl River Delta: An Emerging Regional Economy in a Globalizing China. Hongkong: the Chinese University Press.

Zar JH. 1999. Biostatistical analysis Upper Saddle River, NJ: Prentice-Hall.

Zimmer WMX. 2011. Passive acoustic monitoring of cetaceans. New York: Cambridge University Press 


\section{Figure 1 (on next page)}

Map of the study area.

Acoustic recordings of underwater sounds produced by humpback dolphins were made in Pearl River Estuary and Beibu Gulf. Dashed line area shows the sound recording region. 
Guangxi Province

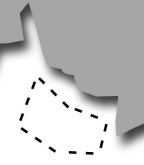
Guang dong province

Pearl River Estuary

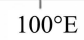

$00^{\circ} \mathrm{E}$ ? 
Figure 2 (on next page)

Schematic of experimental apparatus and the array design.

Acoustic signals was picked by the hydrophones and conditioned by the amplifier and filtered before storage into the PC via the DAQ systems. Distance between $\mathrm{H} 1, \mathrm{H} 2, \mathrm{H} 3, \mathrm{H} 4$, and $\mathrm{H} 5$ was $1.47 \mathrm{~m}$ and $1.54 \mathrm{~m}$ for Pearl River Estuary and Beibu Gulf, respectively. Distance between $\mathrm{H} 1, \mathrm{H} 2, \mathrm{H} 3$, and H4 was $2.08 \mathrm{~m}$ and $2.18 \mathrm{~m}$ for Pearl River Estuary and Beibu Gulf, respectively. The inset shows a detailed view of the hydrophone array. 


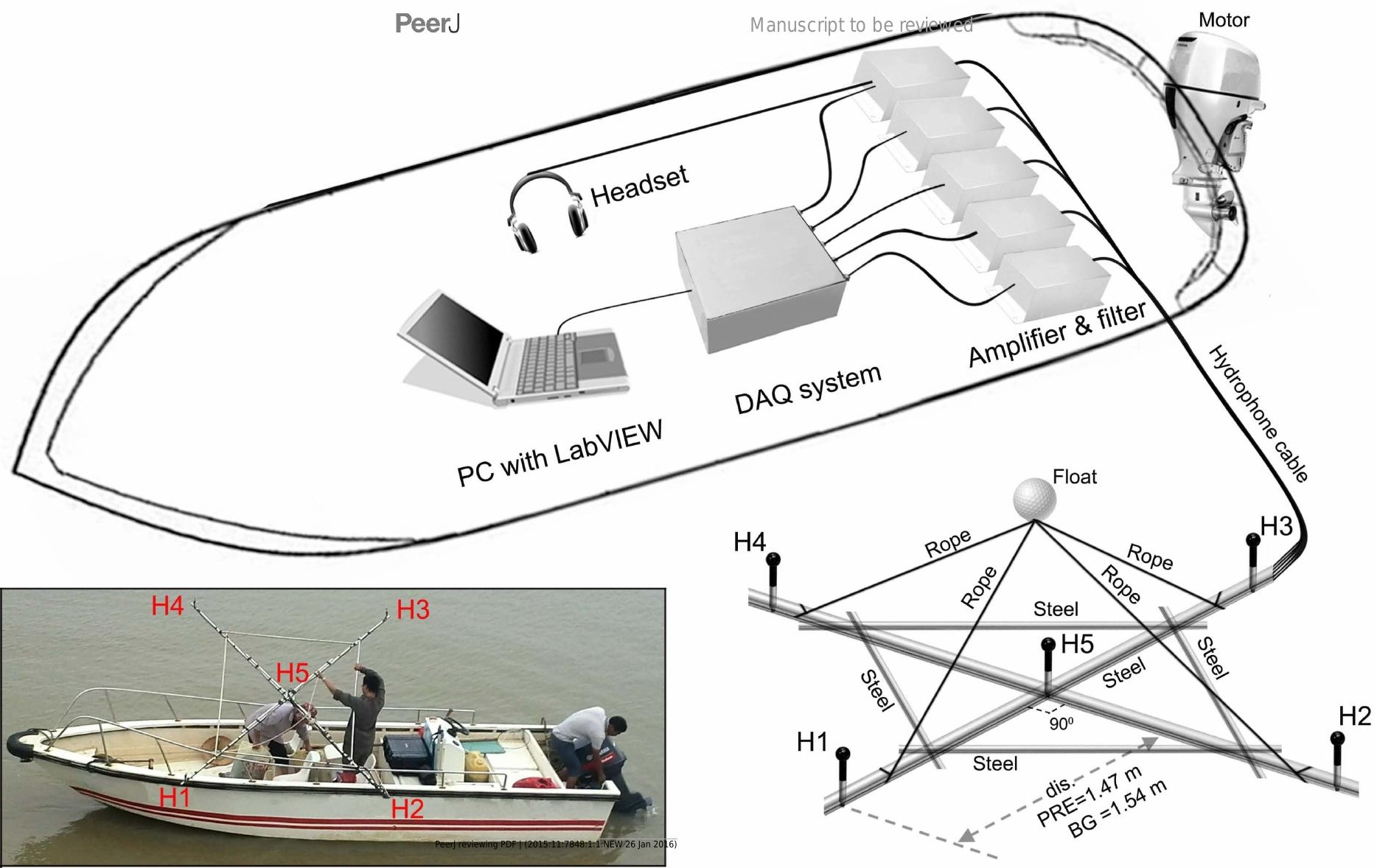




\section{Figure 3 (on next page)}

Schematic of multipath propagation

The $d w, d a$ and dh were the depth of the water, the animal, and the receiving hydrophone, respectively. " $\mathrm{A}$ " denotes the animal location, and " $\mathrm{H}$ " denotes the hydrophone, Aa was the horizontal separation distance between the animal and the hydrophone, $r_{0}$ was the horizontal separation distance between the animal and the hydrophone, $r_{s}(m)$ and $r_{b}(m)$ were the signal propagation lengths for multipath propagation signal with a total number of $m$ reflection points and the initial reflection point at the air-water and water-bottom interface, respectively, $\theta_{s}(m)$ and $\Phi_{s}(m)$ were the incident (same as reflected) and transmitted angle, respectively, for multipath propagation signal with a total number of $m$ reflection points and the initial reflection point at the air-water interface, $\theta_{b}(m)$ and $\Phi_{b}(m)$ were the incident (same as reflected) and transmitted angle, respectively, for multipath propagation signal with a total number of $m$ reflection points and the initial reflection point at the water-bottom interface, $h_{s}(m)$ and $h_{b}(m)$ were the vertical propagation length of the multipath propagation signal with a total number of $m$ reflection points and the initial reflection point at the air-water and water-bottom interface, respectively, by referencing the animal location. The insets show the sound transmission at the air-water interface and at the water-bottom interface, respectively. 
Figure 4 (on next page)

Sound transmission loss coefficient as a function of animal depth and distance between hydrophone and animals at given hydrophone and water depth.

The blue curve was the modeled transmission loss of the whistle with a peak frequency of 6.6 $\mathrm{kHz}$ (see spectrogram in Fig. 5) at water depth of $4.5 \mathrm{~m}$ with hydrophone at $1 \mathrm{~m}$ depth and animal located at (A) surface, (B) middle section and (C) bottom of the water in Beibu Gulf. The red curve in each graph represents logarithmic curve fit of the blue curve. 


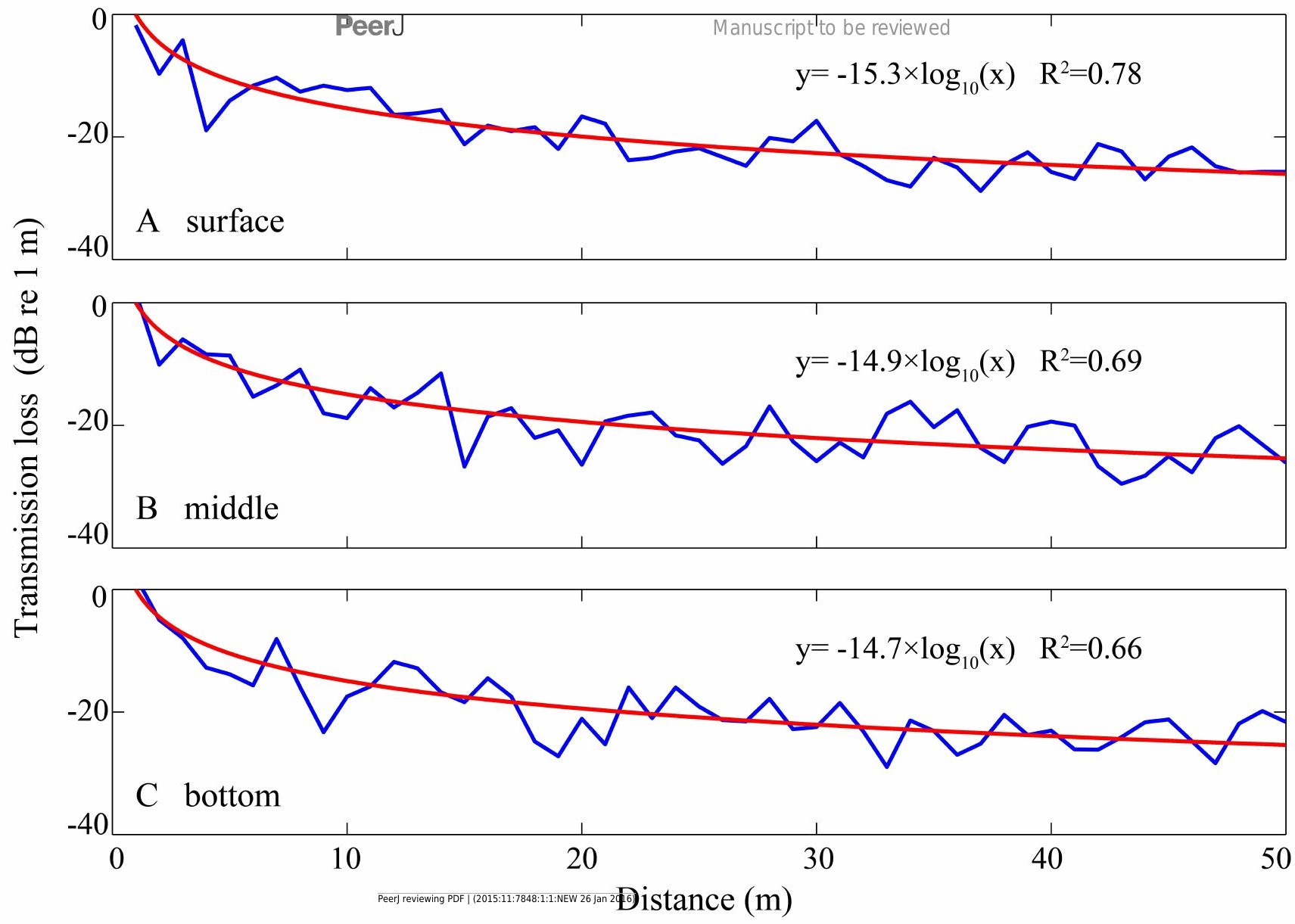




\section{Figure 5 (on next page)}

Schematic of acoustic localization of humpback dolphins whistle.

(A) oscillograms of same signal received at four different hydrophones ( $H 1, H 2, H 3$, and $H 4)$. Cross-correlation was shown in $\mathrm{B}$, and legends on the top left corner of each panel indicate which two hydrophones have been cross-correlated. The peak of each correlation function corresponds to time differences in time of arrival of whistles in the front hydrophone minus that of the later one for the compared hydrophones. Hyperbola fixing (in $\mathrm{C}$ ) and legends next to each hyperbola in indicate which hydrophone pair it corresponds to. Points of intersection of hyperbolae indicate position of sound source. Closed blue circle (in C) indicates position of hydrophone arrays. Point $(0,0)$ was located at the center of the acoustic array. The slide on the top right corner of $(\mathrm{C})$ indicating the depth of the animal. 
Figure 6 (on next page)

Spectrogram of the six whistle tonal types.

Spectrogram configuration (window type: Hanning; temporal grid resolution 5 ms; overlap samples per frame 80\%; frequency grid spacing $24.4 \mathrm{~Hz}$; window size 5 000; FFT size 8 192; Nyquist frequency $100 \mathrm{kHz}$ ). Note that spectrogram maximum frequency was scaled to 25 $\mathrm{kHz}$ for a detailed view of the whistle fundamental frequency. 


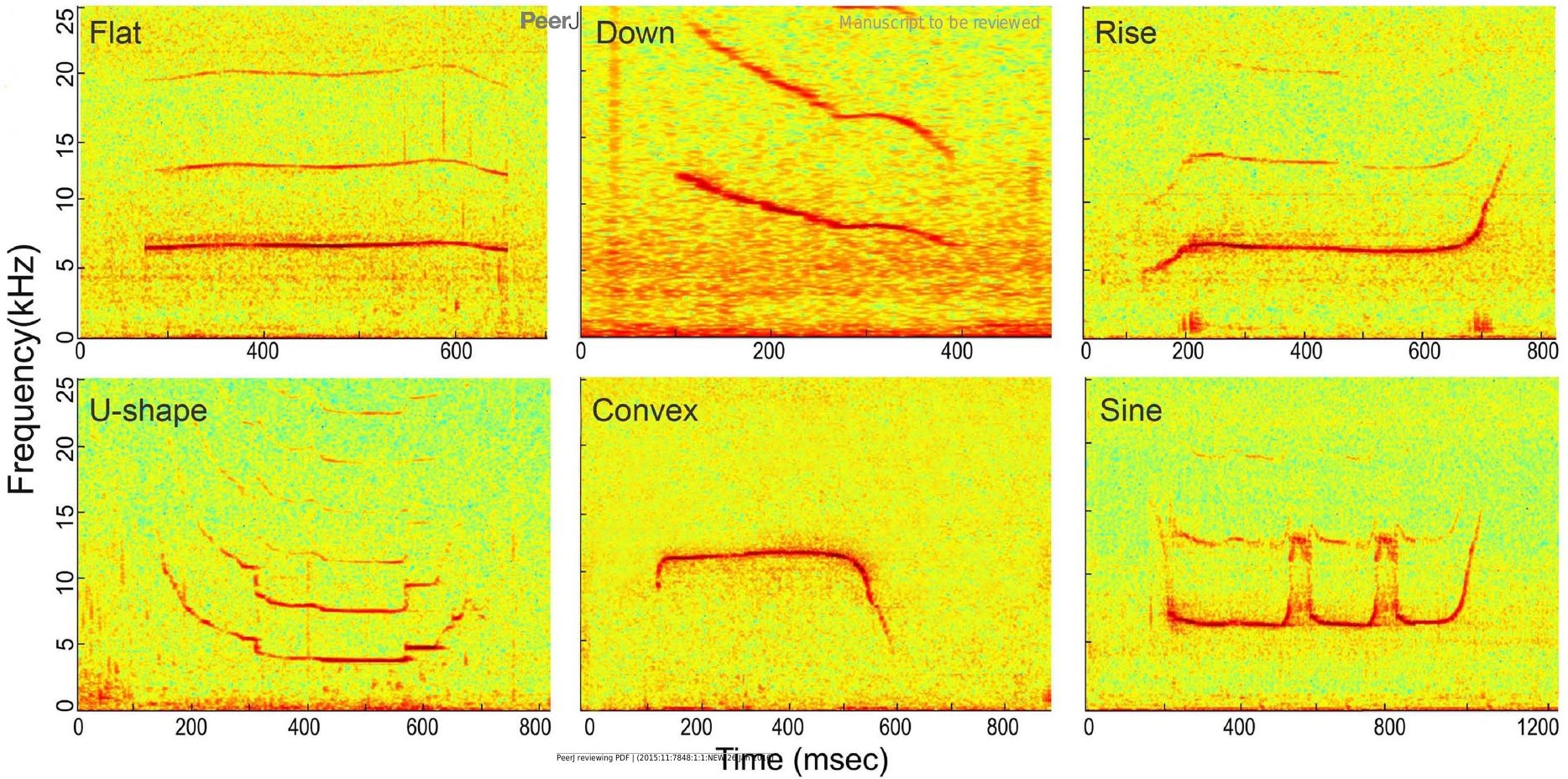




\section{Figure 7 (on next page)}

Three-step whistle extraction.

(A) waveform and (B) spectrogram of the $2 \mathrm{~s}$ signal extracted for each whistle. Candidate whistle was extracted from the starting and ending point of the trace of the whistle fundamental frequency contour (in C) and further extracted as the portion containing $98 \%$ of the total cumulative energy (between $\mathrm{Ce}_{1 \%}$ and $\mathrm{Ce}_{99 \%}$ in $\mathrm{E}$ ), whistle duration was defined as the time between the $1^{\text {st }}$ and $99^{\text {th }}$ cumulative energy percentiles (between $t_{99 \% c e}$ and $t_{1 \% c e}$ in $E$ ). A $500 \mathrm{~ms}$ ambient noise selection (in A and B) was extracted following each whistle as the matched noise. Spectrogram configuration (window type: Hanning; temporal grid resolution 5 ms; overlap samples per frame $80 \%$; frequency grid spacing $31.3 \mathrm{~Hz}$; window size 12821 ; FFT size 16 384; Nyquist frequency $256.414 \mathrm{kHz}$ ). Note that spectrogram maximum frequency was scaled to $20 \mathrm{kHz}$ for a detailed view of the fundamental frequency. 


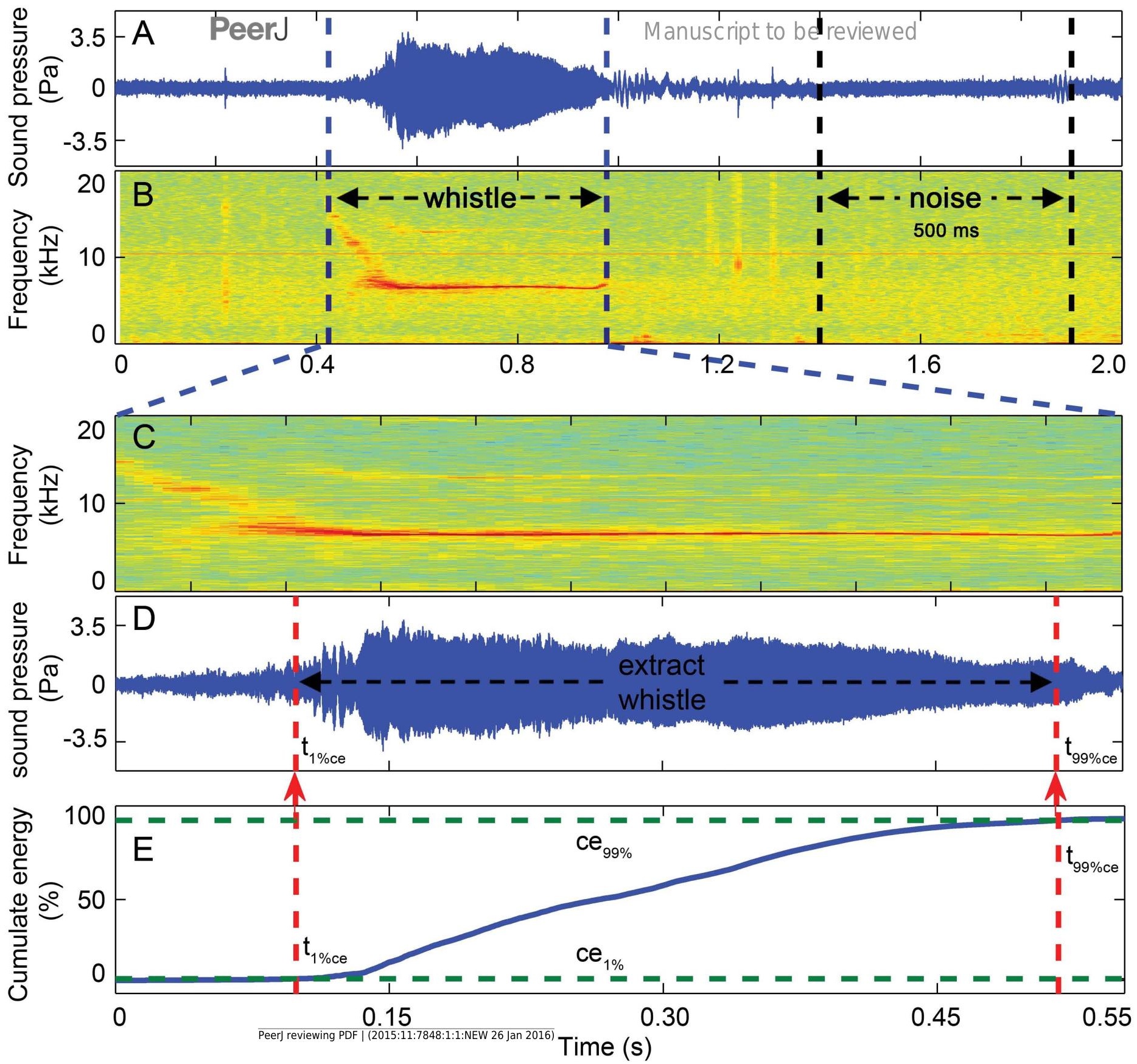




\section{Figure 8 (on next page)}

Schematic for active communication space calculation.

The mean(Sig_TOBL) and mean(Noi_TOBL), surrounded by gray shading of a $95 \% \mathrm{Cl}$ was calculated from a running average of the one-third octave band levels for each whistle and the matched noise, respectively, with step window size of $200 \mathrm{~ms}$ and $95 \%$ steps overlap, fp was the peak frequency determined by the mean(Sig_TOBL), the $\max \left(S_{\text {Sig_TOBL}}\right.$ ) and mean(Noi_PSD) was calculated from a running maximum one-third octave band levels of whistle and a running average power spectral density of the matched noise, respectively, both with step window size of $200 \mathrm{~ms}$ and $95 \%$ steps overlap. Sousa audiogram with a frequency span of $500 \mathrm{~Hz}$ to $38 \mathrm{kHz}$ was obtained by fitting a third-order polynomial curve to the Sousa auditory thresholds between $5 \mathrm{kHz}$ and $38 \mathrm{kHz}$. Dolphin critical ratio was adopted from Johnson et al, 1989. The inset shows a detailed portion of the $\max \left(\mathrm{Sig}_{-}\right.$TOBL) and mean(Sig_TOBL) at the peak frequency determined by the averaged one-third octave band levels for all the $200 \mathrm{~ms}$ slices for each whistle. 


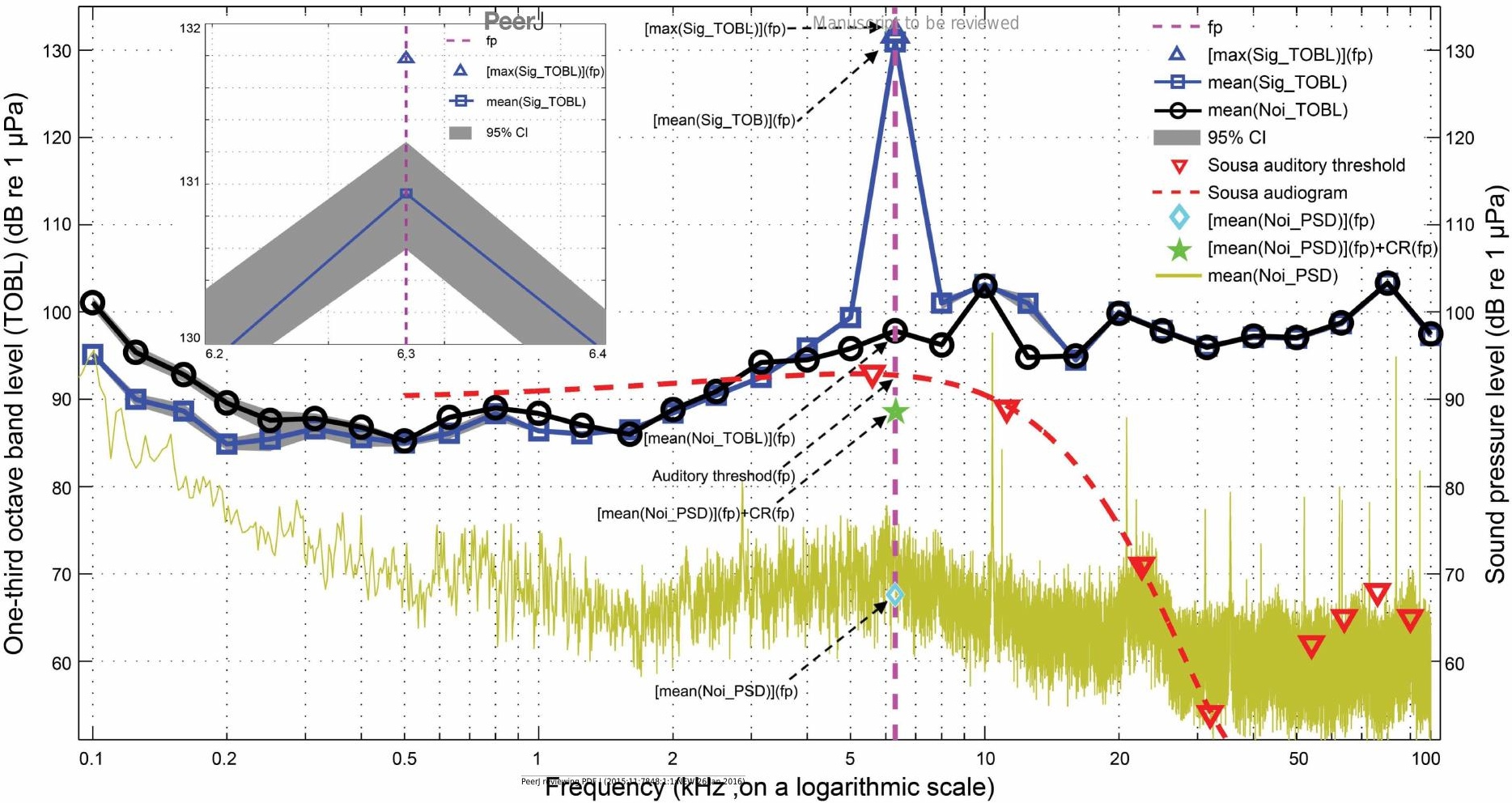


Figure 9 (on next page)

Histogram (A) and box plot (B) of the modeling sound transmission loss coefficient in Pearl River Estuary and Beibu Gulf.

In the box plot, the central line mark on each box is the median, the edges of the box are the first quartile (Q1) and the third quartile (Q3), and the notch indicates the $95 \% \mathrm{Cl}$ of the median. Outliers (Open circles) were the data that is outside the fences of Q1-1.5xinterquartile-range (IQR) and Q3 + 1.5 $\times \mathrm{IQR}$, where IQR=Q3-Q1; Whiskers show the most extreme data points that are not outliers. 
Figure 10 (on next page)

Box plot of the apparent source levels (ASLs) and source energy flux density (SEFD) of the six tonal types.

The center of each box is the median value, the upper and lower box borders are the first quartile (Q1) and the third quartile (Q3). The whiskers extend to the most extreme data within the fences of Q1-1.5 xinter-quartile-range (IQR) and Q3 + 1.5 $\times$ IQR, where IQR=Q3-Q1. Outliers (open circles) were the data outside the fences. The boxes with different lower case and upper case were significantly different at $p<0.05$ and $p<0.01$, respectively, within each apparent source level and source energy flux density categories. 


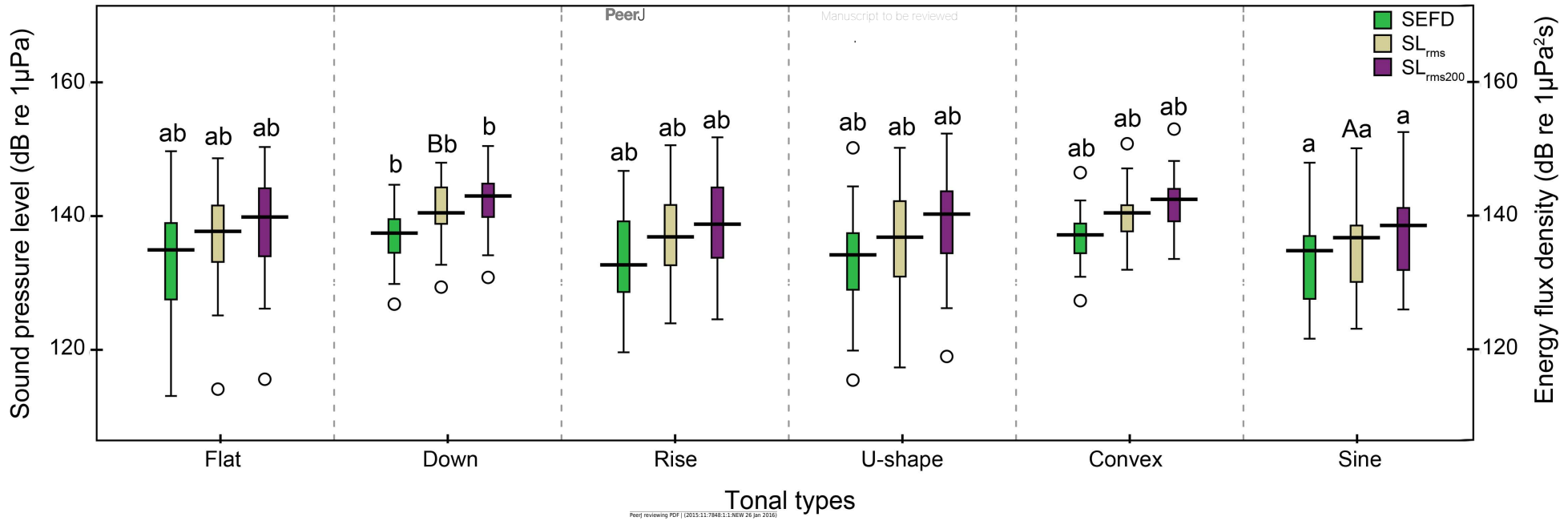




\section{Table 1 (on next page)}

Summary of 14 survey days in Pearl River Estuary and Beibu Gulf.

Each successfully localized whistle was grouped according to tonal types. 


\begin{tabular}{|c|c|c|c|c|c|c|c|c|c|c|}
\hline Site & Date & Sample rate & $\begin{array}{l}\text { Recorded } \\
\text { whistles }\end{array}$ & & & $\begin{array}{l}\text { Localized } \\
\text { whistles }\end{array}$ & & & & \\
\hline & & & & Flat & Down & Rise & U-shape & Convex & Sine & sum \\
\hline \multirow[t]{4}{*}{ PRE } & 20140605 & 200000 & 78 & 21 & 0 & 2 & 0 & 1 & 5 & 29 \\
\hline & 20140708 & 512821 & 5 & 0 & 0 & 0 & 0 & 0 & 0 & 0 \\
\hline & 20140710 & 512821 & 19 & 1 & 0 & 0 & 0 & 0 & 3 & 4 \\
\hline & 20140711 & 512821 & 6 & 0 & 0 & 0 & 0 & 0 & 0 & 0 \\
\hline \multirow[t]{11}{*}{ BG } & 20140804 & 512821 & 35 & 4 & 3 & 2 & 3 & 3 & 4 & 19 \\
\hline & 20140805 & 512821 & 49 & 2 & 2 & 1 & 15 & 1 & 2 & 23 \\
\hline & 20140806 & 512821 & 28 & 5 & 5 & 1 & 1 & 0 & 0 & 12 \\
\hline & 20140813 & 200000 & 107 & 6 & 2 & 2 & 1 & 3 & 1 & 15 \\
\hline & 20140814 & 200000 & 55 & 8 & 1 & 4 & 9 & 1 & 0 & 23 \\
\hline & 20140815 & 200000 & 8 & 1 & 0 & 0 & 0 & 0 & 1 & 2 \\
\hline & 20140816 & 200000 & 4 & 0 & 0 & 0 & 0 & 0 & 0 & 0 \\
\hline & 20140820 & 200000 & 66 & 5 & 3 & 2 & 2 & 2 & 9 & 23 \\
\hline & 20140821 & 200000 & 18 & 0 & 0 & 0 & 0 & 0 & 0 & 0 \\
\hline & 20140822 & 200000 & 156 & 13 & 12 & 14 & 33 & 4 & 16 & 92 \\
\hline & Sum & & 634 & 66 & 28 & 28 & 64 & 15 & 41 & 242 \\
\hline
\end{tabular}




\section{Table 2 (on next page)}

Environmental parameters and the estimated sound propagation speed at the recording site of the Pearl River Estuary and Beibu Gulf. 


\begin{tabular}{|c|c|c|c|c|c|c|c|}
\hline & & Temperature $\left({ }^{\circ} \mathrm{C}\right)$ & Salinity $(\%)$ & $\mathrm{pH}$ & Depth(m) & Velocity $(\mathrm{m} / \mathrm{s})$ & Sediment \\
\hline $\mathrm{PRE}(\mathrm{N}=61)$ & mean $\pm \mathrm{SD}$ & $28.6 \pm 0.7$ & $30.6 \pm 3.7$ & $7.5 \pm 0.4$ & $7.0 \pm 0.9$ & 1538 & Clayey silt \\
\hline & Range & $27.3-30.2$ & $30.1-31.1$ & $6.6-7.9$ & $4.6-9.3$ & \\
\hline $\mathrm{BG}(\mathrm{N}=45)$ & mean $\pm \mathrm{SD}$ & $30.6 \pm 0.4$ & $23.5 \pm 6.0$ & $8.1 \pm 0.1$ & $4.6 \pm 2.0$ & 1535 & Fine sand \\
\hline & Range & $30.1-31.1$ & $20.0-30.0$ & $7.7-8.3$ & $1.9-7.9$ & \\
\hline
\end{tabular}

1 


\section{Table 3 (on next page)}

Descriptive and comparative statistic of the whistle parameters and active communication spaces from Pearl River Estuary and Beibu Gulf.

$t$, whistle duration; ASLs, apparent source levels; fp, peak frequency derived from a running average of the whistle mean one-third octave band levels with step window size of $200 \mathrm{~ms}$ and $95 \%$ overlap; ACS, the active communication space; ACS $_{a t}$, the auditory-threshold limited active communication space. ${ }^{*}$ denote data with a grossly skewed distribution and descriptive parameters of median \pm quartiledeviation and P5-P95 were presented. Bolded numbers indicating significantly different at $p<0.05$. 


\begin{tabular}{|l|l|l|l|l|r|r|}
\hline & PRE $(\mathrm{n}=33)$ & & $\mathrm{BG}(\mathrm{n}=209)$ & & & \\
\hline $\mathrm{t}$ & mean $\pm \mathrm{SD}$ & Range & mean $\pm \mathrm{SD}$ & Range & $\mathrm{z}$ & $\mathrm{p}$ \\
\hline $\mathrm{ASL}_{\mathrm{rms}}$ & $0.50 \pm 0.19$ & $0.23-1.01$ & $0.44 \pm 0.20$ & $0.21-1.61$ & -2.0 & $\mathbf{0 . 0 4}$ \\
\hline $\mathrm{ASL}_{\text {rms200 }}$ & $138.5 \pm 6.8$ & $125-158$ & $137.2 \pm 7.0$ & $114-160$ & -0.8 & 0.42 \\
\hline $\mathrm{SEFD}$ & $140.3 \pm 7.3$ & $126-160$ & $139.3 \pm 6.9$ & $116-161$ & -0.4 & 0.66 \\
\hline $\mathrm{SPL}_{\text {noi }}$ & $135.2 \pm 7.4$ & $121-155$ & $134.0 \pm 6.8$ & $110-158$ & -0.7 & 0.46 \\
\hline $\mathrm{f}_{\mathrm{p}}$ & $122.3 \pm 5.0$ & $111-134$ & $122.2 \pm 6.3$ & $105-132$ & -1.0 & 0.32 \\
\hline $\operatorname{mean}(\mathrm{ACS})^{*}$ & $4.9 \pm 1.0$ & $3.2-8.0$ & $6.1 \pm 2.6$ & $1.6-16.0$ & -3.0 & $<\mathbf{0 . 0 0 1}$ \\
\hline $\max ^{*}\left(\mathrm{ACS}^{*}\right.$ & $14.7 \pm 2.6$ & $3.6-34.6$ & $34.2 \pm 9.5$ & $6.1-76.5$ & -5.5 & $<\mathbf{0 . 0 0 1}$ \\
\hline $\operatorname{mean}\left(\mathrm{ACS}_{\mathrm{at}}{ }^{*}\right.$ & $17.1 \pm 3.5$ & $3.9-39.8$ & $43.5 \pm 12.2$ & $7.2-119.2$ & -5.8 & $<\mathbf{0 . 0 0 1}$ \\
\hline $\max \left(\mathrm{ACS}_{\mathrm{at}}{ }^{*}\right.$ & $24.3 \pm 4.8$ & $6.9-65.3$ & $60.7 \pm 18.1$ & $6.8-142.6$ & -4.2 & $<\mathbf{0 . 0 0 1}$ \\
\hline & $37.5 \pm 4.6$ & $7.4-76.5$ & $74.3 \pm 25.3$ & $8.1-198.1$ & -4.4 & $<\mathbf{0 . 0 0 1}$ \\
\hline
\end{tabular}

1 


\section{Table 4 (on next page)}

Apparent source level of dolphin and whale whistles.

All source levels were in rms, except those from the study of Fish and Turl (1976), of which power spectrum range were given. ${ }^{a}$ animal moving with or towards the array; ${ }^{b}$ animal moving ahead of or away from the array; ${ }^{\mathrm{c}}$ limited by the recording system; ${ }^{\mathrm{d}}$ measured from power spectrum generated by peak hold method; ${ }^{e}$ measured from $95 \%$ energy window; ${ }^{f}$ $90 \% \mathrm{Cl} ;{ }^{9}$ measured from $200 \mathrm{~ms}$ running windows; ${ }^{\mathrm{h}}$ measured from power spectrum generated by sum-average method; ' measured from $100 \mathrm{~ms}$ running window; ' measured by cross-correlation functions; ${ }^{\mathrm{k}}$ measured from the $98 \%$ energy window; ' measured from 200 ms running window. 


\begin{tabular}{|c|c|c|c|c|c|c|}
\hline Species & Latin name & Source & Location & Mean $\pm \mathrm{SD}(\mathrm{dB})$ & Range (dB) & Sample size \\
\hline \multirow[t]{3}{*}{$\begin{array}{l}\text { Hawaiian Spinner } \\
\text { dolphins }\end{array}$} & $\begin{array}{l}\text { Stenella } \\
\text { longirostris }\end{array}$ & $\begin{array}{l}\text { Watkins and } \\
\text { Schevill (1974) }\end{array}$ & $\begin{array}{l}\text { Kealakekua Bay, } \\
\text { Hawaii }\end{array}$ & & 109 to 125 & $\mathrm{~N}=14$ \\
\hline & & $\begin{array}{l}\text { Lammers and } \mathrm{Au} \\
(2003)\end{array}$ & Coastal of Oahu, Hawaii & $153.9 \pm 4.5^{\mathrm{a}}$ & & $\mathrm{N}=22$ \\
\hline & & & & $150.2 \pm 2.8^{\mathrm{b}}$ & & $\mathrm{N}=22$ \\
\hline \multirow[t]{6}{*}{$\begin{array}{l}\text { Bottlenose } \\
\text { dolphin }\end{array}$} & $\begin{array}{l}\text { Tursiops } \\
\text { truncatus }\end{array}$ & Tyack (1985) & $\begin{array}{l}\text { Captive in aquariums, } \\
\text { US }\end{array}$ & & $125->140^{c}$ & \\
\hline & & $\begin{array}{l}\text { Fish and Turl } \\
\text { (1976) }\end{array}$ & $\begin{array}{l}\text { Offshore Southern } \\
\text { California waters }\end{array}$ & & $150-173^{\mathrm{d}}$ & \\
\hline & & Janik (2000) & Moray firth, Scotland & $158 \pm 6.4$ & $134-169$ & $\mathrm{~N}=103$ \\
\hline & & Jensen et al (2012) & $\begin{array}{l}\text { Koombana Bay, } \\
\text { Western Australia }\end{array}$ & $146.7 \pm 6.2^{\mathrm{e}}$ & $136.8-158.0^{\mathrm{f}}$ & $\mathrm{N}=180$ \\
\hline & & & & $147.6 \pm 6.4^{\mathrm{g}}$ & $137.9-159.0^{\mathrm{f}}$ & $\mathrm{N}=180$ \\
\hline & & $\begin{array}{l}\text { Frankel et al } \\
(2014)\end{array}$ & Gulf of Mexico & $138.2 \pm 8.0$ & $114-163$ & $\mathrm{~N}=645$ \\
\hline Common dolphin & $\begin{array}{l}\text { Deiphinus } \\
\text { delpliis }\end{array}$ & $\begin{array}{l}\text { Fish and Turl } \\
(1976)\end{array}$ & $\begin{array}{l}\text { Offshore Southern } \\
\text { California waters }\end{array}$ & & $125-145^{h}$ & $\mathrm{~N}=385$ \\
\hline $\begin{array}{l}\text { Atlantic spotted } \\
\text { dolphin }\end{array}$ & $\begin{array}{l}\text { Stenella } \\
\text { frontalis }\end{array}$ & $\begin{array}{l}\text { Frankel et al } \\
(2014)\end{array}$ & Gulf of Mexico & $138.4 \pm 8.0$ & $115.4-163.1$ & \\
\hline \multirow[t]{2}{*}{$\begin{array}{l}\text { white-beaked } \\
\text { dolphins }\end{array}$} & $\begin{array}{l}\text { Lagenorhync } \\
\text { hus } \\
\text { albirostris }\end{array}$ & $\begin{array}{l}\text { Rasmussen et al } \\
(2006)\end{array}$ & Faxafloi Bay, Iceland & $148 \pm 12^{\mathrm{i}}$ & $124-166$ & $\mathrm{~N}=12$ \\
\hline & & & & $144 \pm 8^{j}$ & $118-167$ & $\mathrm{~N}=43$ \\
\hline Baiji & $\begin{array}{l}\text { Lipotes } \\
\text { vexillifer }\end{array}$ & Wang et al (2006) & Shishou reserve, China & $143.2 \pm 5.8$ & $135.9-150.8$ & $\mathrm{~N}=43$ \\
\hline \multirow[t]{2}{*}{$\begin{array}{l}\text { Humpback } \\
\text { dolphin }\end{array}$} & $\begin{array}{l}\text { Sousa } \\
\text { chinensis }\end{array}$ & Present study & PRE and BG, China & $137.4 \pm 6.9^{\mathrm{k}}$ & $114-160$ & $\mathrm{~N}=242$ \\
\hline & & & & $139.5 \pm 6.9^{1}$ & $116-161$ & $\mathrm{~N}=242$ \\
\hline $\begin{array}{l}\text { Short- } \\
\text { finned pilot whale }\end{array}$ & $\begin{array}{l}\text { Globicephala } \\
\text { macrorhynch } \\
\text { us }\end{array}$ & $\begin{array}{l}\text { Fish and Turl } \\
\text { (1976) }\end{array}$ & $\begin{array}{l}\text { Offshore Southern } \\
\text { California waters }\end{array}$ & & $157-183^{d}$ & \\
\hline Killer whale & Orcinus orca & Miller et al ( 2006) & Johnstone strait, Canada & $140.2 \pm 4.1$ & $133-147$ & $\mathrm{~N}=24$ \\
\hline
\end{tabular}

1 